\title{
Empathy: Its ultimate and proximate bases
}

\author{
Stephanie D. Preston and Frans B. M. de Waal \\ Department of Psychology, University of California at Berkeley \\ Living Links, Yerkes Primate Center and Psychology Department, Emory University, Atlanta
}

Address correspondence to S. Preston, Department of Psychology, University of California, Berkeley, CA 94720-1650, USA.

Email: spreston@ socrates.berkeley.edu . Phone: 510-643-3572. Fax: 510-642-5293.

\section{Short abstract}

The empathy literature is characterized by debate regarding the nature of the phenomenon. We propose a unified theory of empathy, divided into ultimate and proximate levels, grounded in the emotional link between individuals. On an ultimate level, emotional linkage supports group alarm, vicariousness of emotions, mother-infant responsiveness, and the modeling of competitors and predators; these exist across species and greatly effect reproductive success. Proximately, emotional linkage arises from a direct mapping of another's behavioral state onto a subject's behavioral representations, which activate responses in the subject. This ultimate and proximate account parsimoniously explains different phylogenetic and ontogenetic levels of empathy.

\section{Long abstract}

The empathy literature has been characterized by disagreement regarding the exact nature of the phenomenon. There are emotional, cognitive, and conditioning views of empathy, and these views apply to different extents across species. We argue that with an adequate description of the ultimate and proximate mechanism, these views can be cohered into a unified whole. We use an interdisciplinary approach along ultimate and proximate levels for a unified theory grounded in the fact that individuals are behaviorally, physiologically and neurologically linked. These forms of emotional linkage support group alarm, vicariousness of emotions, mother-infant responsiveness, and the modeling of competitors and predators; these exist across species and have profound effects on reproductive success. Proximately, emotional linkage arises from a direct mapping of another's behavioral state onto a subject's representations, which activate behavioral and physiological responses in the subject. With this "Perception-Action Model" (PAM) and an understanding of the way representations change with experience, we can explain the major effects on empathy of similarity, familiarity, past experience, explicit teaching and salience and we can form predictive theories about the variety of empathy disorders. Furthermore, by elaborating on the interaction between the PAM and prefrontal functioning, we can explain different levels of empathy attainable across species and age groups. This unified view advances the evolutionary account of empathy beyond inclusive fitness and reciprocal altruism and the mechanistic account beyond "imaginative projection" or even physiological linkage. This view parsimoniously explains different levels of empathy across individuals, species, stages of development and situations.

\section{Key words: empathy; emotion; perspective taking; emotional contagion; cognitive} empathy; comparative; evolution; altruism; perception-action; human

\section{Introduction}

The concept empathy has had a difficult history, marked by disagreement and discrepancy. Although it has been studied for hundreds of years, with contributions from philosophy, theology, developmental psychology, social and personality psychology, ethology, and neuroscience, the field continues to suffer from a lack of consensus regarding the nature of the phenomenon. Superficially, the debate stems from a lack of consensus on the definition, with a preponderance of research and theory directed towards determining if empathy is an emotional or cognitive process and 
distinguishing empathy from emotional contagion, sympathy, and perspective taking (e.g. Eisenberg 1986; Feshbach 1975; Hornblow 1980; Hoffman 1978; 1982; Omdahl 1995; Shantz 1975; Wispé 1986). On a deeper level, however, the debate seems to stem from the lack of a proximate mechanism. Abstract and elusive definitions like "putting oneself in the place of another" or "imaginatively projecting oneself into the situation of another" (Allport 1937; Buchheimer 1963; Demos 1984; Goldie 1999; Smith 1989) are indicative of an insufficient understanding of or interest in the way the nervous system instantiates empathy. Thirty years ago G. W. Allport said it best when he concluded, "the process of empathy remains a riddle in social psychology...The nature of the mechanism is not yet understood" (Allport 1968, p. 30 from Wispé 1987, original italics).

This, however, is an auspicious time, marked by a proliferation of both interdisciplinary research and tools for understanding the brain. By incorporating a century of empirical behavioral research on empathy with our more recent understanding of physiology and neuroanatomy, we believe that a proximate mechanism can be fully articulated. In addition, this proximate mechanism can be combined with behavioral research on emotional development and comparative research on empathy for an ultimate level description that addresses the evolution and function of empathy. Through an interdisciplinary perspective, examining both the ultimate and proximate bases of empathy, the various perspectives can be fused into a unified whole. The emotional levels of empathy can be linked with the cognitive levels and empathy in humans can be linked with empathy in non-human animals.

\subsection{Common definitions}

For the purpose of clarity, common definitions are provided for emotional contagion, sympathy, and empathy (e.g. Eisenberg \& Strayer 1987; Hoffman 1982; O'Connell 1995; Wispé 1986, Table 1).

Emotional contagion refers to an emotional state in an observer (hereafter the subject) as a direct result of perceiving the state in another (hereafter the object). Emotional contagion includes the spreading of all forms of emotion from one individual to another (e.g. the spreading of joy or distress through a crowd). The present paper however, in keeping with most research in the field, focuses on the contagion of distress. The level of distress of the subject in emotional contagion is generally high and self-focused, also referred to as "personal distress" in the human literature (e.g. Eisenberg et al. 1994). The distinction is lost between the subject and object; both are distressed to a level that precludes appropriate helping behaviors. Empathy refers to situations in which the subject has a similar emotional state to an object as a result of perceiving the object's situation. Empathy is thought to preserve the distinction between self and other, with an emotional state that is object-focused. This may result in succorant or prosocial actions to alleviate the distress of the object. As a process, one is empathizing when they understand the state of the object by activating their own representation of the object's state. As an outcome, one is empathizing when actions are aimed to mitigate the object's distress. Sympathy refers to a state in which the subject feels "sorry for" the object as a result of perceiving the distress of the object. It differs from empathy and emotional contagion because it can be arrived at without a matching emotional response. The subject's state is object-focused and may result in succorant or prosocial actions to alleviate the object's distress. Authors from before the 1950's often use the word "sympathy" for what is currently referred to as "empathy". Cognitive empathy refers to situations when the subject arrives at an understanding of the object's state through cognitive processes. It implies that the subject has used cognitive perspective taking to project him or herself into the position of the subject to understand, empathize and provide help. Because cognitive empathy requires perspective taking, it has been reserved for individuals who can pass traditional tests of perspective taking, usually humans after the age of two years and sometimes apes (e.g. Gopnik \& Meltzoff 1994; Kummer et al. 1996; Povinelli et al. 1992a; 1993; Ungerer 1990).

\section{Term Definition Self-other distinction? State matching? Implications for helping?}

Synonyms

Emotional contagion Similar emotion is aroused in the subject as a direct result of perceiving the emotion of the object. Lacking Yes None Personal distress, Vicarious emotion, emotional transfer

Sympathy Subject feels "sorry for" the object as a result of perceiving the distress of the object. Intact No Depends on the costs and benefits of the situation.

Empathy Subject has a similar emotional state to an object as a result of the accurate perception of the object's situation or predicament. Intact Yes Increasing with familiarity/similarity of object and salience of display.

Cognitive empathy Subject has represented the state of the object as a result of the accurate 
perception of the object's situation or predicament, without necessary state matching beyond the level of representation. Intact Partial, because it can be arrived at in a "top-down" fashion, involving emotional circuits to a lesser extent. Likely, because it is more likely to be invoked for familiar/similar objects. True empathy, Perspective-taking

Prosocial behaviors Actions taken to reduce the distress of an object. Depends Not necessarily Inherent Helping, succorance

TABLE 1: Usage of terminology by most current researchers divided into main variables of classification.

\subsection{Problems with this terminology}

The distinction between empathy and emotional contagion is empirically based and provides good guidelines for categorizing behavior. Individuals who are overly distressed tend not to help while individuals that are emotionally involved and concerned tend to help (Batson et al. 1987; Doherty 1997; Eisenberg et al. 1994; 1998; Eisenberg \& Okun 1996; Rice 1964). However, these heuristics should not cause one to overemphasize the distinction between emotional contagion and empathy. The two share their underlying process and cannot be totally disentangled (as also suggested by Thompson 1987). For example, it is a mistake to assume that one cannot simultaneously be highly distressed and maintain the self/other distinction. Similarly, it is a mistake to assume that one who offers help through empathy is not also acting to diminish negative affect. By design, empathy involves some level of emotional contagion and personal distress (at least at the representational level), and helping is never entirely for the sake of the object.

"State-matching" is another term too strongly differentiated in the literature. According to some, the subject has to have the same state as the object for empathy to take place (e.g. Feshbach and Roe 1968). Because our proximate model involves a direct-perception approach to empathy, state matching depends on the extent to which the subject has accurately perceived the state of the object. Perception is inherently subjective, thus, the likelihood of a perfect match is virtually nonexistent and accuracy cannot be discretely assigned.

We argue that it is more useful to consider empathy as a broad phenomenon that encompasses identification, emotional contagion, and cognitive empathy (Figure 1). All of these are processes whereby an individual employs the brain's way of understanding the world to understand the internal states of others. The state of the object is modeled in the subject because the relevant representations of state, situation, person, and expression are activated. This in turn activates responses, which may or may not be appropriate for helping the subject or the object, depending on the situation. This mechanism is crucial for group alarm, vicariousness of emotions, mother-infant responsiveness, modeling of competitors and predators, and theory of mind processes. The ultimate and proximate descriptions will elaborate on this viewpoint.

Figure 1: In order to unify the various perspectives, empathy needs to be construed broadly to include all processes that rely on the emotional linkage between individuals.

\subsection{Historical perspective}

0.3.1. Proximate bases. In order to see how the concept of empathy has become so tangled, and how it can be untangled, a historical perspective is necessary. The original German word Einfülung, of which the English "empathy" is Titchener's translation (1909; Wispé 1991, p. 78), literally means "feeling into," (Wispé 1986). Historically, however, people have used sympathy more commonly to describe what now falls under the rubric of empathy. Einfülung was thought to result from a process where observers project themselves into the objects they perceive (Lipps 1903; Titchener 1909; McDougall 1908/1923). Theodore Lipps was the first to put forth a mechanistic account of Einfülung (1903). According to Lipps, the perception of an emotional gesture in another directly activates the same emotion in the perceiver, without any intervening labeling, associative, or cognitive perspectivetaking processes. Since then, however, two paths have diverged from the original Einfülung.

Some theories subsequent to Lipps' have focused on the direct perception aspect. These theories focus on the basis of empathy in emotional contagion or imitation (e.g. Brothers 1990; Hatfield et al. 
1993; Hume 1888/1990; Levenson 1996; Levenson \& Reuf 1992; Nietzsche 1895/1920; Smith 1759; Wermlund 1949). For example, in his Introduction to Social Psychology, McDougall observes "that the behavior of one animal, upon the excitement of an instinct, immediately evokes similar behavior in those of his fellows who perceive his expressions of excitement" (1908/1923, p. 93). He cites examples of children smiling in response to a smile from mother, people feeling tenderness watching a mother-infant interaction, and chimpanzees aroused by the distress of a conspecific.

Other theories emphasize the reverse, making use of Lipps' projection, imitation and imagination, without the direct perception. This makes empathy a higher-level, cognitive phenomenon, reserved for humans (e.g. Allport 1961; Feshbach 1978; Freud 1922/1945; Mead 1934; Titchener 1915). Within this ideological camp, there are comparative theories of empathy that have taken this even farther, making empathy synonymous with "perspective taking" (e.g. Povinelli et al. 1992a and b), and limiting empathy to species that exhibit theory of mind (cf. Premack and Woodruff 1978).

Neurological evidence from studies of motor behavior and emotion processing support Lipps' theory of empathy, based on the essential and direct link between perception and action in the brain. This view postulates a common representational code for perceiving and instigating goal-directed actions (reviewed by Prinz 1987; 1992; 1997; Rizzolatti and Arbib 1998). If the common coding approach is applied to the study of empathy, with an understanding of the way representations change with experience, the model can accommodate both the emotional and cognitive accounts as well as behaviorist/conditioning accounts (e.g. Allport 1924; Becker 1931; Church 1959; Scheler 1923/1954). Thus, the proximate level explanation of empathy will elaborate a neurological mechanism for empathy that consists of the "Perception-Action Model" (PAM), and a description of the role of representations in empathy.

0.3.2. Ultimate bases. Former attempts at describing the ultimate bases have also been wrought with problems, but of a different nature. Ultimate accounts are notorious for being cursory and speculative. Moreover, previous evolutionary models of empathy did not reference important empirical research available in animals and humans and dealt only with one aspect or one level of the phenomenon. For example, many propose that emotional contagion exists to facilitate the motherinfant bond (Darwin 1998/1872; McDougall 1908/1923; Plutchik 1987). Because emotional contagion is thought related to empathy, the mother-infant bond is transitively used as an evolutionary explanation for empathy. While we agree that the mother-infant bond is crucial for developing empathy, this argument alone does not link emotional contagion to "true empathy" or cognitive empathy or explain why it would be adaptive to experience empathy for non-offspring. Alternatively, many propose that inclusive fitness and reciprocal altruism explain altruism (Axelrod 1984; Hamilton 1964; Maynard Smith 1964; Trivers 1974). Because altruism and empathy are considered related, inclusive fitness and reciprocal altruism are expected to explain empathy. However, inclusive fitness and reciprocal altruism were developed to support the tendency to refer to certain behaviors as "altruistic", to show that altruism could have evolved. Moreover, altruism is an interpretation of a behavior, not a quantifiable behavior like helping, nor a process like empathy. This ultimate description deals specifically with empathy in all its levels of complexity, and addresses how it may have evolved. It is also provided to inform the proximate level model, as the two are intricately related.

Our Ultimate Bases section details the importance of a direct emotional linkage across individuals. This behavioral, physiological and neurological linkage is important for predator detection in groupliving animals, for establishing the mother-infant bond, determining the state of a predator or conspecific; indeed, any theory of mind processes where the state of another is represented. Empirical research on rodents, monkeys, apes, humans, and individuals with empathy disorders supports the continuity of this linkage across species. As species become more altricial and prefrontal cortex is expanded, these rudimentary forms of linkage can be used to support more cognitively complex forms of empathy and for extending empathy towards non-offspring and non-kin group members.

Stressing the emotional linkage between individuals on both ultimate and proximate levels makes for a parsimonious description of empathy. The benefits of being emotionally linked are directly tied to reproductive success, and the proximate mechanism itself relies on an adaptive organization of the nervous system. Responses are automatically generated from perception, and information is processed and represented egocentrically, through the substrates of self-action. This allows individuals to understand and represent others, it does so with fewer connections, and it facilitates 
appropriate responses from inputs. Thus, combining an ultimate and a proximate description of empathy greatly changes the argument for adaptation, allows one to link different levels of empathy, and exhibits the inherent relationship between these levels. Because research reviewed in the Ultimate Bases section is necessary for understanding the Proximate Bases section, we will address the ultimate first.

\section{The ultimate bases of empathy}

Many animals react with obvious emotional expressions to the distress of conspecifics and will act to terminate the stressor or soothe the object of distress. Intriguing parallels exist between the development of empathy in young humans and the phylogenetic emergence of empathy (Hoffman 1990; de Waal 1996, respectively). Moreover, humans and other animals exhibit the same robust effects of familiarity, past experience, and cue salience (Table 2). These effects suggest that empathy is a phylogenetically continuous phenomenon, as suggested by Charles Darwin over a century ago ("Many animals certainly sympathize with each other's distress or danger," (Darwin 1871/1982), p. 77).

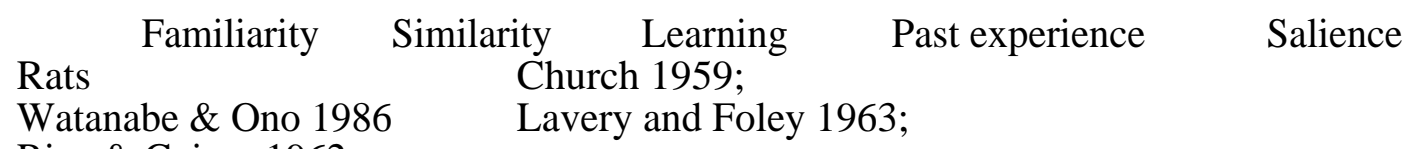

Rice \& Gainer 1962

Monkeys $\quad$ Aureli et al. 1989; Aureli et al. 1992; Cords \& Thurnheer 1993; Demaria \& Thierry 1992; Masserman et al. 1964; Miller et al. 1959 Miller et al. 1966; Miller et al. 1967; Miller et al. 1959 de Waal 1996; de Waal et al. 1996 Masserman et al. 1964; Miller et al. 1967 Miller et al. 1959; Miller \& Deets 1976

Apes O'Connell, 1995; $\quad$ Yerkes \& Yerkes $1929 \quad$ Povinelli et al. 1992a

O'Connell, 1995

Human infants Martin \& Clark 1982; Zahn-Waxler et al.; 1982; Simner 1971

Capps \& Sigman 1996; Thompson 1987; Lamb \& Zakhireh 1997

Human children Zahn-Waxler 1982; Zahn-Waxler et al. 1984; Farver \& Branstetter 1994;

Howes \& Farver $1987 \quad$ Feshbach \& Roe 1968; Rosekrans 1967; Shantz 1975; Smith 1988;

Krebs 1970; Eisenberg et al. 1983; Radke-Yarrow 1983; Trivers 1974; Ungerer 1990; Zahn-Waxler

et al. 1984; Murphy 1937 Eisenberg et al. 1990; Eisenberg et al. 1993;

Human adults Cialdini et al. 1997; Sawyer 1966; (Stinson \& Ickes 1992) Batson et al. 1981; Krebs 1975; Toi \& Batson 1982; Gruen \& Mendelson $1986 \quad$ Aronfreed 1968; Gruen \&

Mendelsohn 1986; Stinson \& Ickes 1992; $\quad$ Aronfreed 1965; Eisenberg et al. 1991; Eisenberg et al.

1994; Gouldner 1960

TABLE 2: Cross-species references for five main empathy literature findings. Empathy increases with Familiarity (subject's previous experience with object), Similarity (perceived overlap between subject and object e.g. species, personality, age, gender), Learning (explicit or implicit teaching), Past experience (with situation of distress), and Salience (strength of perceptual signal e.g. louder, closer, more realistic etc.).

Despite these parallels, the human empathy literature rarely references the animal behavior literature, or accedes to any connection between empathy in humans and in other animals (from here on called animals). This is due partly to the reluctance of students of animal behavior to refer to emotions, and partly to the assumption that human empathy requires higher cognitive processes that are presumed absent or little developed in other animals. Here we explore the comparative evidence, assuming that empathy manifests itself at many different levels of complexity, some of which are clearly within the cognitive reach of many social animals.

\subsection{Adaptation}

Why is it adaptive for individuals to be emotionally affected by displays of distress in conspecifics? There are classic theoretical arguments for the adaptiveness of helping, notably inclusive fitness, reciprocal altruism and the benefits of group esteem (Hamilton 1964; Trivers 1971). These theories were developed to explain why humans would help unrelated individuals and have been reviewed extensively elsewhere, so will not be dealt with in detail here (Hamilton 1964; Krebs 1970; Trivers 1971, de Waal 1996). We suggest, that the evolution of empathy per se is more related to the evolution of emotional linkage between individuals than to the evolution of altruism. 
It is important to note that inclusive fitness, reciprocal altruism, group esteem and emotional linkage are all complementary factors that would additively increase the likelihood of helping behaviors. Indeed, empathy, helping and degree of closeness are correlated with decreasing tendencies from kin to close friends, acquaintances, and strangers (Cialdini et al. 1997) and altruistic behavior in experimental situations is directed at friends more than neutral individuals (Sawyer 1966). But with our model, inclusive fitness and reciprocal altruism did not drive the selection for empathy, instead, they facilitate external acts of helping after empathy is evoked or in the absence of empathy. The following sections will elaborate on the existence of emotional linkage across species and its effect on reproductive success.

\subsubsection{Emotional linkage as a requirement for group living. McDougall, noted that} empathy appears to exist in group-living animals, or those with the "gregariousness instinct", because these animals are innately affected by the emotions of others (McDougall 1908/1923). According to McDougall's theory, sympathy "is the cement that binds all animal societies together, renders the actions of all members of a group harmonious, and allows them to reap some of the prime advantages of social life" (McDougall 1908/1923, p. 93). For example, if one group member sees something dangerous, usually a predator, an alarm call is given and in most cases the group moves away from the source of danger en-masse. Thus, the alarm of one individual alarms others. This phenomenon is well-documented for many species, including ground squirrels (e.g. Sherman 1977), birds (e.g. Powell 1974), and monkeys (e.g. Cheney \& Seyfarth 1985). Given this behavior, danger is more likely to be detected even though each individual spends a smaller proportion of their time on vigilance (Powell 1974; Kenward 1978). The "more eyes" phenomenon allows individuals to spend more time on other activities that promote reproductive success such as feeding and finding mates. The evolutionary importance of detecting and responding to danger is evident in the general design of the nervous system. Response circuits are dedicated to the perception of distress and the biological substrates for processing negative emotions, especially fear, have been easy to locate relative to positive ones (e.g. Adolphs, et al. 1994; 1995; Ekman et al. 1983; Miller et al. 1966; Scott et al. 1997).

The vicariousness of activity, often seen in group-living animals, is also symptomatic of the innate response to emotion in others. Wild dogs, for example are described as nosing, licking, squeaking and jumping at each other before the onset of a hunting expedition (van Lawick-Goodall \& van Lawick-Goodall 1971). Similarly, in rhesus macaques, a severely distressed infant will often cause other infants to approach, embrace, mount or even pile on top of the victim; the distress seems to spread to the other infants who then seek contact to soothe their own arousal (de Waal 1996). This type of emotional contagion is also the first stage of empathic responding in humans, exemplified when infants in a nursery cry in response to other infants' cries (Sagi \& Hoffman 1976; Simner 1971) and year-old children seek comfort after witnessing the injury of another (Hoffman 1990; Zahn-Waxler et al. 1992).

1.1.2. Emotional linkage facilitates the mother-offspring bond. Dyadic relationships, especially the parent-child relationship, are characteristic of the emotional or physiological linkage between individuals (as noted by others, including Darwin 1998/1872; McDougall 1908/1923 and Plutchik 1987). Infants are emotionally affected by the state of their mothers and mothers are emotionally affected by the state of their offspring, in behavior and physiology.

1.1.2.1 Effects of the mother on the infant. Continuous and coordinated emotional and physical contact between the mother and infant are thought to organize the emotion regulation abilities of the infant, which determine the emotional competence of the individual (e.g. Brazelton et al. 1974; Deboer \& Boxer 1979; Gable \& Isabella 1992; Levine 1990; Stern 1974; 1977).

On a neurophysiological level, maternally-separated rat pups show reduced levels of growth hormone $(\mathrm{GH})$ and a peripheral biochemical block between $\mathrm{GH}$ and the enzymatic activity required for cell protein synthesis. This can be reversed with appropriate stimulation. After 24 hours of separation, the sleep of these rat pups is also disturbed, due to the lack of entraining interactions with the mother (Hofer 1995; 1999). Separation causes arousal and the release of stress hormones in attached primate infants and mothers (Levine 1990). Rhesus macaques raised without their mother lack the normal, adaptive relationship between behavior and neurochemistry in response to stress (Kraemer and Clarke 1996). In humans, infants of depressed mothers have reduced left hemisphere activation (Jones et al. 
1998) and lack the normal increase in vagal tone between 3 and 6 months that is correlated with vocalizations and optimal neurological functioning (Field et al. 1995).

Behavioral development has also been shown to rely on the mother-infant relationship. Isolate monkeys are impaired at sending and receiving emotional expressions to normally-developing conspecifics (Miller et al. 1967), a task easily done by normally-developing individuals (Miller et al. 1962; 1963). The expressive impairments of the isolate animals is compared by many to that of humans with autism, who are also impaired at the communication of affect (e.g. Bemporad 1987; Harlow \& Harlow 1966; Miller et al. 1967). Infants of depressed mothers are impaired at matching happy facial and vocal expressions (Lundy et al. 1997) and show less orientation and fewer facial expressions in response to modeled happy and surprise expressions (Lundy et al. 1996).

We argue that the emotional link between individuals subserves the ability of infants to perceive and learn from the expressions of the caregiver. For example, through the perception-action link, the actions and expressions of the mother are mapped onto existing representations of the infant and generate actions and expressions in response (elaborated on below). This facilitates not only the infant's ability to understand the behavior of the mother, but also facilitates coordinated activity in the dyad, necessary for the development of emotion regulation.

Infants and their caretakers are thought to use their emotional expressions to reinforce positive affect, transform negative affect and provide breaks when arousal becomes too high (Malatesta \& Haviland 1982; Tronick 1989). Such responsiveness is thought to organize behavior (Campos et al. 1983) and create a sense of security and efficacy (e.g. Bell \& Ainsworth 1972). The coordinated activity between caregiver and infant seems required for emotional regulation and control (Field 1994), which are in turn required for empathic competence throughout life (Ungerer 1990). A lack of coordinated activity may contribute to behavioral problems associated with an inability to assess and control emotions, such as tantrums, poor impulse control, and risk-taking (Tronick 1989). In humans, fear and personal distress lead to self-directed efforts and, thus, are prohibitive of empathy, sympathy, and perspective taking (Eisenberg et al. 1994). Emotion regulation problems are correlated with personal distress and a lack of helping in preschoolers, older children, college undergraduates and the elderly (Doherty 1997; Eisenberg et al. 1996; Eisenberg \& Okun 1996; Eisenberg et al. 1994, respectively). Similarly, when albino rats witness a conspecific lifted hoisted off of the ground, they will press a bar to eliminate the distress of the other animal. But when they witness a conspecific being shocked, they do not press the bar. The latter situation is interpreted as being too stressful for the subjects, precluding an empathic response (Rice 1964). Thus, without emotional linkage or the interactions necessary to develop its capacities, infants can not learn to regulate their emotions and the development of more advanced forms of empathy are compromised.

Emotional linkage can also teach offspring about their environment. If an infant is aroused by the display of emotion in the parent (especially fear or distress), then the infant can use the mother's reaction as an unconditioned stimulus to learn about danger. For example, if an infant monkey is aroused by the arousal of a parent in the presence of a snake, it can learn to fear snakes without the need for a more costly direct experience (Mineka \& Cook 1988; 1993; Mineka, et al. 1984).

Normally-developing 12-month-old children social reference the mother in the face of ambiguity (Feinman 1982; Klinnert et al. 1983). When presented with a loud toy in the lab, children this age approach the toy if the mother smiles but approach the mother if she expresses fear. Similarly, when infants approach a visual cliff, social referencing to the mother determines whether or not the infant will cross (Sorce et al. 1985). Implicating emotional linkage, these infants display negative affect after referencing a mother with a fearful expression (Klinnert et al. 1983; Sorce et al. 1985). The mother's emotion is adaptively perceived and incorporated into the offspring's actions without necessitating the same level of response (as in alarm) or direct experience (as required by conditioning models, e.g. Allport 1924; Church 1959). Social referencing studies have found negative emotions to affect the behavior of infants much more than positive. This is in accordance with findings from other fields, and with the importance of alarm and distress contagion on reproductive success.

1.1.2.2. Effects of the infant on the mother. It is also adaptive for the parent to be affected by the emotional state of the infant. In the ethological literature, Eibl-Eibesfelt postulates that the evolution of parental care in birds and mammals created not only actions by the parent to care for offspring, but concurrent actions by the offspring to request care (1972/1974). Interactional views of development similarly postulate that the infant directs the mother's behavior as much as the mother 
directs the infant's (Bell 1968; 1971; Brazelton et al. 1974; Osofsky 1971; Wiesenfeld \& Klorman 1978; Yarrow, et al. 1971). Smiling and crying by the infant are thought to modify the affective and behavioral responses of their caregivers. Such behaviors signal the infant's state, providing the impetus for attention and action (Acebo \& Thoman 1995; Bowlby 1958; 1969). Illustrating the importance of infant-to-mother communication, a female chimpanzee at a zoo lost a succession of infants despite intense interest because she was deaf and did not correct positional problems (such as sitting on the infant, or holding it the wrong way) in response to soft distress calls (de Waal 1982). What is the mechanism for such interpersonal communication?

Crying and smiling can induce autonomic arousal in the caregiver that simultaneously acts as an unconditioned stimulus to motivate a response and as the precursor stimulation for the response (Wiesenfeld and Klorman 1978). When rat pups are separated, they produce ultrasonic vocalizations that instigate the mother to search for, retrieve and return the pups to the nest (Smotherman et al. 1978). Crying in human infants elicits high levels of maternal attention in postnatal weeks with high, continued levels of maternal stimulation (Acebo and Thoman 1992). High levels of crying associated with colic cause distress in parents (e.g. Liebman 1981; Meyer and Thaler 1971; Rowell 1978). Mothers are physiologically aroused when witnessing their own infant crying; they show an increase in heart rate and large skin conductance responses. The crying of a strange infant elicits the standard orienting response (Wiesenfeld and Klorman 1978).

Because physiological arousal in the child causes arousal in the mother and vice versa, emotional contagion increases the success of both individuals by proximately guiding the parent-offspring relationship. If a similar emotion is elicited in the subject as in the object (as posited by the proximate model and supported by physiological data), then tailored care is much more likely. Proper care surely increases viability of the offspring and, thus, the reproductive success of the parent. Fulfilling the needs of the offspring also assuages the arousal of the caregiver and offsets the unwanted attention from group members and predators caused by an individual displaying distress.

Although emotional displays can coordinate, regulate and guide the parent-child relationship, care is often provided in the absence of such releasers. What is the mechanism for these acts of helping? The association between a context and its outcome is known to be facilitated by emotional arousal (e.g. Corodimas and LeDoux 1995). Therefore, still without invoking cognitive empathy, contagious distress from offspring to parent can act as an unconditioned stimulus, motivating the parent to act before a stressful display erupts. For example, captive and wild ungulate species approach their calves for nursing before a request is emitted (Murdock et al. 1983). Further, through empathy, the parent can identify with the offspring, providing care when conditioned associations to personal experience dictate it necessary. Again, the parents (indirectly) and the offspring (directly) benefit because the offspring's needs are satisfied without the cost of unwanted attention and a stressful display.

Emotional displays can continue to indicate the needs of altricial offspring into adolescence. Temper tantrums, an extreme example, are used by offspring to direct the behavior of the caregiver even after their needs diverge (Einon and Potegal 1994; Trivers 1974) Tantrums that include "screaming, crouching, hurling self on ground, running and occasionally attacking the mother" are common in young humans and chimpanzees (Einon and Potegal 1994). The temper tantrum endangers reproductive success by causing respiratory distress, damage to the vocal folds and involving selfinflicted injury (Einon and Potegal 1994; Potegal and Davidson 1997), but it is a successful technique because the parent is averse to any loud display, and the high-pitched scream of the tantrum signals appeasement and recruits help (similar to that of a subordinate animal under attack) (Potegal and Davidson 1997).

The preceding evidence suggests that the emotional linkage between parent and offspring has a profound effect on reproductive success. It provides an unconditioned access to the infant's emotional state, and thus the need as well as the motivation to help. It conditions offspring to know when and how to request care and conditions parents to know when and how to provide care. Thus, the direct emotional link between individuals is highly adaptive for group-living individuals, especially those that provide extended care. This direct link also provides the basis for empathy and helping outside of these contexts.

\subsubsection{Emotional linkage between unrelated conspecifics.}


1.1.3.1. Emotional contagion, empathy and helping. Empathy may have a phylogenetic and ontogenetic basis in the emotional linkage between parent and offspring, but empathy is exercised across the lifespan in many mammals. How is empathy extended from these rudimentary forms of emotional linkage?

Empathy in alarm and parent-offspring situations was described as resulting from innate releasing stimuli. High pitched sounds that resemble alarm calls or screams induce fast action in situations of immediate physical danger, while sounds that resemble crying induce action for less immediate needs like food, comfort, and warmth. These same stimuli can be used to elicit empathy and helping from non-offspring. A distressed chimpanzee, for example, who has just lost a major battle will "pout, whimper, yelp, beg with outstretched hand, or impatiently shake both hands" in order to solicit the consolatory contact of others (de Waal and Aureli 1996). Eibl-Eibesfeldt argues that the infantile releasers of caregiving are used throughout adult life, such as the use of a high-pitched voice or "baby names" between lovers (Eibl-Eibesfeldt 1972/1974).

In animals and humans, distress in an object evokes distress and helping in the subject, even when the two are not related (evidence below). In what ways it is beneficial to extend innate releasing mechanisms and care-giving beyond the parent-child relationship? Because releasers elicit distress in the receiver through the direct emotional link, they can initiate the actions of potential allies and terminate the actions of predators and conspecific attackers. It is mistaken to argue whether help is given for the benefit of the object or to terminate the aversive distress signal of the object or the "caught" distress of the subject. Aversive signals evolved because, by definition, others want them terminated. The comparative evidence below attests to the success of these signals in soliciting help from conspecifics, especially in cases where the subject and object are familiar with each other or the subject is familiar with the situation of distress (for a more detailed review of this literature see Preston and de Waal submitted).

1.1.4 Cognitive empathy. Kuni, a bonobo female at the Twycross Zoo in England, once captured a starling. She took the bird outside and gently set it onto its feet, the right way up, where it stayed looking petrified. When it didn't move, she threw it a little, but it just fluttered. Not satisfied, Kuni picked up the starling, climbed to the highest point of the highest tree, and carefully unfolded the bird's wings, one wing in each hand, before throwing it as hard as she could into the air. When the bird still remained in the enclosure, Kuni guarded it for a long time against a curious juvenile (de Waal 1997b, p. 156).

Cognitive empathy appears to emerge developmentally and phylogenetically with other "markers of mind" (Gallup 1992; 1979; Povinelli et al. 1994; Premack and Woodruff 1978), including perspective taking (PT), mirror self-recognition (MSR), deception, and tool-use. Some argue that cognitive forms of empathy in animals reflect social facilitation and/or conditioning (Galef 1992; Heyes 1993a; 1993b; Tomasello and Call 1997). Regardless, the behavioral complexity and flexibility of these behaviors is greatly increased in humans and apes relative to other primates and most mammals. Only humans after certain ages and the great apes have been cited as passing tests for the markers of mind and evincing higher than 1st order intentionality (cf. Dennett 1988; for a review see Byrne and Whiten 1988, O'Connell 1995; Tomasello and Call 1997).

Although enhanced perspective taking abilities and cognitive empathy surely increase reproductive success, the basic capacity to be emotionally linked to others probably existed at least as far back as the evolution of group-living, and may even be part of the general design of the nervous system of all animals. Thus, the basic capacity for empathy existed long before these more cognitive abilities became available. The cognitive capabilities can, however, augment emotional linkage to support more complex forms of empathy.

"Markers of mind" and cognitive empathy are associated with larger proportional prefrontal region. The protracted development of Hominoid species increases the extent of learning before adulthood and is speculated to result in the disproportionate increase in the prefrontal cortex (Finlay \& Darlington 1995). Working memory, planning and behavioral inhibition are processes known to be subserved by the prefrontal cortex (for reviews see Fuster 1997; Shiamamura 1996; Thierry et al. 1994) and these abilities facilitate cognitive empathy. For example, increases in working memory could allow for simultaneous representation of the subject's and object's state, facilitating perspective 
taking. An increase in prefrontal cortex can also allow the subject to inhibit distress associated with representing the object. This will be elaborated on in the Proximate Bases section below.

\subsection{Comparative Data}

1.2.1. Emotional contagion, empathy and helping. As discussed above, albino rats faced with the distress of a conspecific hoisted off of the ground pressed a bar to terminate the object's distress (Rice \& Gainer 1962). These subjects spent each trial close to and oriented towards the distressed object. This "altruism effect" could not be replicated using looped recordings of rat squeaks as the stimulus (Lavery \& Foley 1963). In contrast to the "altruistic" bar pressing in the hoist experiments, rats faced with the distress of a conspecific being shocked decrease bar pressing (Church 1959; Rice 1964). A decrease in bar pressing by the subject is an indication of fear (cf. Estes \& Skinner 1941). A fear interpretation is bolstered by the behavioral data as these subjects "typically retreated to the corner of their box farthest from the distressed, squeaking, and dancing animal and crouched there, motionless, for the greater part of this condition" (Rice 1964, p. 167). According to an emotional linkage theory of empathy, the subject is distressed because the state of the object is imparted to him directly through emotional linkage. Although this fear response rapidly adapted, subjects that previously experienced shock themselves greatly decreased bar pressing for at least 10 days (the duration of the experiment). Thus, consistent with Church's conditioning model, the prior experience with shock facilitated and augmented the natural distress response. These effects were replicated with pigeons (Watanabe \& Ono 1986).

Rhesus monkey subjects also pressed a bar to avoid witnessing the shock of a conspecific object. Subject-object pairs were conditioned to expect a shock to the object after illumination of the compartment. In these cases, the object "leap[t] and [ran] around whenever its compartment was illuminated". Seventy-three percent of the time, the subject pressed the bar to this agitation alone, displaying "piloerection, urination, defecation and excited behavior" (Mirsky et al. 1958, p. 437). After the subjects' response was extinguished, it could be reinstated using pictures of monkeys, but not using the shock of a live albino rat or the thrashing of a monkey-like puppet (Miller et al. 1959). The response to pictures was less strong and clear than to the live animals, but the response was stronger to pictures of familiar monkeys than unfamiliar (Miller et al. 1959). These results replicate those from rats and pigeons. After learning the consequences of shock, the monkeys were aroused by the sight of a conspecific in distress, acted to eliminate the suffering of the stimulus animal, but were not responsive to artificial or unfamiliar stimuli.

Closer to altruism, monkeys refrained from rewarded actions if it caused another monkey to receive a shock (Wechkin et al. 1964). In one task, 10 out of 15 animals preferred a non-shock chain even though this resulted in half as many food rewards as the shock chain (Masserman et al. 1964). Of the remaining 5 subjects, one stopped pulling both chains altogether for 5 days and another for 12 days after witnessing the shock of the stimulus animal. These animals were literally starving themselves to keep the other animal from being shocked. Again, subjects who had previously experienced shock or were familiarity with the object were more likely to sacrifice food rewards (Masserman et al. 1964).

Chimpanzees also show emotional contagion-like responses to the displays of conspecifics. In one experiment, subjects were shown three types of videos, depicting positive, negative and neutral stimuli (play, severe aggression and scenery, respectively). The subjects responded to the aggression tapes with "piloerection, pant-hoots, and bluff-displays", to the positive play videos with "play faces, body gestures and solicitations to the video monitor that indicated an initiation of play", and to the control tapes with "strong visual orientation...but no indication of social arousal." (Parr \& Hopkins in press). In a similar experiment, peripheral skin temperature decreased (indicating greater negative arousal) when subjects viewed videos of conspecifics injected with needles or videos of needles themselves, but not videos of a conspecific chasing the veterinarian (Parr submitted).

The effects from empathy studies in rats, pigeons, monkeys and apes are replicated in human studies. The most robust findings are for familiarity or similarity of the subject with the object and previous experience with the distress situation (Table 2). Human subjects who witness the shock of a conspecific offer to take the shocks for the object if they were made to feel similar though demographic descriptions. If they do not feel similar, they only offer to take the shocks if they have to watch the object receive the remaining shocks (e.g. Batson et al. 1981, Toi \& Batson 1982). The same interaction occurred with an attribution paradigm (Batson et al. 1981). In another paradigm, 
male subjects presented with an object that won money or was shocked showed more of a physiological response, identified with the object more, reported more distress to the shock and helped more when they were made to feel similar (Krebs 1975).

1.2.2. Cognitive empathy. The previous examples portray the basic emotional linkage between individuals, and its role in motivating helping. However, much of the research on empathy focuses on cognitive empathy. Comparative evidence of cognitive empathy focuses on data on consolation and anecdotal reports of helping in apes.

Consolation involves contact initiation by a previously uninvolved bystander who is assumed to be less distressed, and directs consolatory efforts to the victim (first defined as such by de Waal \& van Roosmalen 1979). It has not been found in monkey species despite intensive efforts to find it (de Waal \& Aureli 1996). Conclusions are based on analyses of hundreds of post-conflict observations that compare third-party contact tendencies with baseline rates (de Waal \& van Roosmalen 1979; de Waal \& Aureli 1996). One can postulate that the consoling individual has become distressed from the sight of the victim and seeks comfort for his or her own feelings. While some level of distress in the subject is inherent in our model, the consoler often does not show overt signs of distress, and may wait until after the most intense display to approach (de Waal \& Aureli 1996) (Figure 2).

Figure 2: A juvenile chimpanzee comforts a distressed adult.

The tailored helping of Kuni the bonobo (above) or of Binti Jua, an 8-year-old female western lowland gorilla who rescued a 3-year-old boy at the Brookfield Zoo (de Waal 1997a), are also wellknown examples of tailored helping that indicate cognitive empathy in apes. Anecdotal accounts are subject to bias, but an analysis of over 2,000 anecdotal reports of non-human primate empathy revealed three types of empathy in chimpanzees: emotional, concordance (like cognitive empathy) and extended (tailored helping) (O'Connell 1995). Understanding excitement, grief/sadness/frustration and fear of the subject were extremely common, with most outcomes resulting in the subject comforting the object of distress. Chimpanzees comprehend the emotions, attitude and situation of another and even endangered their lives to save others in danger. An adult male chimpanzee died trying to rescue an infant who had fallen over the electric fence into a moat. Monkey displays of empathy, by contrast, were restricted to mediation of fights, adoption of orphans, and reactions to illness and wounding.

\section{The Proximate Bases of Empathy}

\subsection{The Perception-Action Model (PAM) and Mirror Neurons \\ "The fact was overlooked that, in order to express it, the body must in the last analysis become the thought or intention that it signifies for us"}

-Merleau-Ponty, Phenomenology of Perception (1962/1970, p. 197).

In his Phenomenology of Perception, Merleau-Ponty argues that the mental and the physical are a unity, and as such do not exist independently of each other (Merleau-Ponty 1962/1970). He describes the "intentional arc" whereby inputs are directly mapped to outputs, without the necessity of intervening goals. Thus he writes, "In normal imitation, the subject's left hand is immediately identified with his partner's, his action immediately models itself on the other's, and the subject projects himself or loses his separate reality in the other, becomes identified with him..." (1962, p. 141). Dreyfus elaborates on the intentional arc, describing how skill acquisition relies on the tuning of responses to inputs until automaticity is achieved (Dreyfus 1996).

The "Perception-Action Hypothesis" (a term used by researchers of motor behavior) is grounded in the theoretical idea, adopted by many fields over time, that perception and action share a common code of representation in the brain (reviewed by Allport 1987; Prinz 1987; 1992; 1997; Rizzolatti \& Arbib 1998). According to the perception-action hypothesis, perception of a behavior in another automatically activates one's own representations for the behavior, and output from this shared representation automatically proceeds to motor areas of the brain where responses are prepared and executed. This organization makes sense if perceptual systems evolved to provide accurate 
information about the environment to appropriately plan and guide movements (Prinz 1992). These common codes are not necessarily restricted to physical movements, but may include abstract, symbolic representations (Decety et al. 1997; Jeannerod 1994; Prinz 1997). What is the evidence for the PAM in the motor literature?

2.1.1. Evidence for the PAM. Many experiments in cognitive psychology support the direct link between perception and action. The development of cognitive neuroscience tools including brain imaging, single cell recording, Electroencephalograms (EEG), Transcranial Magnetic Stimulation (TMS), and patient studies, has resulted in a spate of experiments testing the Perception-Action Model (PAM).

Evidence suggests that sensory inputs are automatically processed to a response phase. In a responsecompetition paradigm where human subjects have to choose an action based on the features of the stimulus on each trial, event-related potentials (ERP) measures suggest that partially analyzed sensory information is passed to the response phase even though the perceptual analysis is not complete (e.g. Hommel 1997; reviewed in Hillyard 1993). The results were replicated using single-unit recordings in the macaque monkey (Miller et al. 1992). Reaction-time (RT) data with a similar paradigm confirms the covert preparation of responses (Craighero et al. 1998). Similarly, when subjects have to perform two stimulus-response tasks simultaneously, the response to the second stimulus seems to be prepared before the response to the first is completed, supporting an "automatic translation hypothesis" (Hommel 1998).

Premotor neurons are thought to retrieve the appropriate motor acts in response to sensory stimuli. Particular neurons in the rostral-most part of the premotor area (F5) are active during goal-directed hand movement such a reaching and grasping. Interestingly, a class of these cells fire when a monkey observes others making these actions (di Pellegrino et al. 1992; Jeannerod et al. 1995). These "mirror neurons" are thought to represent goal-directed actions, allowing individuals to understand and imitate the actions of others (Rizzolatti \& Arbib 1998). In a brain-imaging study using Positron Emission Tomography (PET), observing an action with the intent to imitate it activated the areas used in planning and performing the actions (bilateral dorsolateral prefrontal cortex and pre-supplementary motor area) (Decety et al. 1997). In an fMRI study, the left inferior frontal cortex and the rostral-most part of the right superior parietal lobule were activated when subjects observed a finger movement and when initiating the same movement under different conditions. Further, activation was highest when the subject made the movement in response to observing the movement in another (i.e., the area was activated by the observation in addition to the movement). The results are interpreted by the authors as support for the common code or "direct matching" hypotheses of perception and action. Taken with the F5 data (above), the they suggest that the left frontal areas code the goal of movements and would thus be necessary to understand the meaning of one's action. The right parietal area would then code the precise movements involved and would be necessary for memorizing or repeating actions (Iacoboni et al. 1999).

These shared representations for perception and action are also activated when a movement is imagined (Jeannerod 1996; 1995; Jeannerod \& Frak 1999). Response times (RTs) for imagining walking in a 3-dimensional environment follow Fitt's Law, increasing with increasing distances and difficulty (Decety \& Jeannerod 1995). In addition, much evidence supports a common representation for mental and manual rotation. RTs for imagining and performing a rotation movement are virtually identical (Wohlschläger \& Wohlschläger 1998). Further, task interference and facilitation in the rotation task occur only at a high level of motor processing (thereby increasingly involving the planned execution of actions) (Wohlschläger \& Wohlschläger 1998). When given the choice of two stimuli to rotate, the majority of subjects choose the object corresponding to their preferred hand (Cook et al. 1994). RTs for a left-right hand orientation judgment are similar for doing and imagining the movement (Parsons 1994). Further, in a PET brain-imaging study, premotor, somatosensory and cerebellar regions were activated when subjects imagined moving their hands (Parsons et al., 1995).

Beyond perception or imagination of the action per se, these motor representations seem to be activated when people perceive or think about objects that have movements associated with them. For example, naming and observing common tools activates the left premotor cortex (Grafton et al. 1997), an area involved with the planning of movements in response to stimuli, where learned motor sequences might be stored. Therefore, even relatively abstract cognitive affordances of objects may be partially coded with respect to their appropriate motor acts, or at least activate the representation of the 
appropriate motor responses.

Taken together, actions that are self-generated, perceived in another, imagined, or even suggested by an object seem to activate shared representations. These shared representations may be at the abstract level of meaning, but they are linked downstream with areas responsible for the performance of the action. Activation is thought to spread from the representation of the meaning to that of the performance if there is no inhibition, but the extent to which motor sequences are activated depends on the mode of input, salience of and attention to the stimulus, and extent of inhibitory control (addressed further below).

In humans, the link between observed and generated actions seems circumscribed to the left hemisphere (Rizzolatti \& Arbib 1998). Broca's area, which might be the human homologue to area F5 in monkeys, is active in PET studies during the execution and imagination of hand and arm movements (reviewed by Rizzolatti and Arbib 1998). In one study, grasp observation activated the superior temporal sulcus, the inferior parietal lobule and the inferior frontal gyrus, while grasp imagination activated Broca's area (area 44), caudal inferior parietal cortex (area 40), rostral SMA proper and dorsal PMC (all in the left hemisphere only) and the middle frontal cortex (Grafton, et al. 1996). The authors concluded that the areas activated by the observation of a grasping movement may contribute to the recognition of such movements while the areas active in the imagination of grasping contribute to the actual production of grasping movements (Grafton et al. 1996).

The following section will address the extent to which this data can be applied to a proximate mechanism of empathy. The major findings in the empathy literature are recontextualized in light of the PAM so that a coherent model can be created that incorporates prior theories and empirical findings with the ultimate model and this emerging zeitgeist in cognitive neuroscience.

2.1.2. The PAM and empathy. Previous theoretical accounts of empathy have implicated a perception-action model to varying degrees (Adolphs 1999; Boodin 1921; Levenson \& Reuf 1992; Lipps 1903; McDougall 1908/1923; Meltzoff \& Moore 1997). Lipps' theory (1903) was the forerunner of the perception-action model in motor behavior and he explicitly implicated it in empathic processes. Similarly, McDougall stated, "sympathy is founded upon a special adaptation of the receptive side of each of the principal instinctive dispositions, an adaptation that renders each instinct capable of being excited on the perception of the bodily expressions of the excitement of the same instinct in other persons". Mirror neurons and the perception-action theory have also been speculated recently to be involved in imitation (Iacoboni et al. 1999) and for understanding the states of others, or theory of mind (Adolphs 1999; Gallese \& Goldman 1998).

Less directly implicating perception-action processes, Levenson and Reuf (1992) suggested that the heart-rate concordance between subjects in affect communication paradigms could be the basis for empathy; this coheres with our claim that the PAM induces similar states in the subject and object, but does not include the central nervous system components. Meltzoff and colleagues suggested their AIM model for imitation could be applied to the development of empathy (e.g. Meltzoff \& Moore $1977 ; 1983 ; 1994)$. This differs from the PAM only in the directness by which representations are activated (described further below). Gallup suggested that information about the self is used to model the states of others. Without an explicit mechanism, his "introspective" model seems implicitly more cognitive. The object's state is not mapped automatically onto the subject's representations and the process is reserved for species that exhibit theory of mind processes (Gallup 1998).

Experiments in the psychological literature that measure heart rate, electromyograms (EMG), brain activity, adult human behavior and development lend credence to the idea that understanding the emotion of others entails to some degree experiencing the emotion observed (as also suggested by Brothers 1990).

2.1.2.1. Physiological and neurological evidence. Heart rate data in humans and monkeys is correlated within a subject when perceiving and producing a response and between subjects when affect is communicated. Humans experience the same physiological changes participating in a conversation and watching it later from video (Gottman \& Levenson 1985). Macaques have the same heart rate response experiencing distress or receiving the distress from the expression of another (Miller et al. 1966). The successful communication of affect in monkey and human subjects requires an equivalent heart rate in receiver and sender (Miller et al. 1967; Levenson \& Reuf 1992, 
respectively). This "physiological linkage" has been speculated to be the physiological substrate for empathy (Levenson \& Reuf 1992).

Electrical recordings of facial muscles (EMG) also support the PAM; people exposed to pictures of emotional facial expressions spontaneously activate the valence-appropriate muscles (Dimberg 1982;1990). Pictures of happy faces elicit zygomatic major muscle activity and angry faces elicit corrugator supercilii activity (Dimberg \& Thunberg 1998), even when the pictures are processed outside of awareness (Dimberg et al. 2000). Moreover, subjects in a similar experiment reported feeling an emotional reaction, consistent with the emotion displayed and the muscles activated (Lundqvist \& Dimberg 1995).

Patients with lesions in the right somatosensory cortex have great difficulty labeling the basic emotions and making intensity judgments from photographs (Adolphs, et al. 1997; 2000). The authors speculate that in some way, it is necessary to ask, "how would my body feel if I were making that face", in order to do the task.

The fact that the left hemisphere is most often affected in the former motor studies while the right hemisphere is selectively implicated in emotion processing is not problematic for the PAM. If it is a general principle of the nervous system that perception activates response, then it follows that the particular hemisphere involved depends on the characteristics of the stimuli. The hemispheric difference literature has found, broadly speaking, that the left hemisphere (in right-lateralized subjects) processes detailed information while the right hemisphere is selective for more holistic information (reviewed by Liotti \& Tucker 1995). Related to the PAM, the left prefrontal area is thought more active in response to semantic cues, the right when responses must be generated from memory, and both when the task requires generating voluntary or imagined actions (Decety et al. 1997). Related to emotional processing, the right hemisphere may process all emotional stimuli (Gur et al. 1994; Lane et al. 1999; Schwartz et al. 1975), or the right hemisphere may subserve fearful or negative emotions while the left subserves positive (e.g. Canli et al. 1998; Davidson \& Ehrlichman 1980). Supporting the lateralization of emotions in our closest relative, chimpanzees shown positive, negative, and neutral videos (described above), showed increased brain temperatures in the right hemisphere to the negative videos depicting severe aggression, (Parr \& Hopkins in press). Future research specifically aimed at delineating the perception-action circuit for empathy and emotion processing can confirm any hemispheric specialization.

2.1.2.2. Behavioral evidence. Behavioral data in humans also support the idea that the emotion of the object is imparted to the subject. For example, in a six-condition experiment, subjects attend either to an object in need or the potential helper, when help is given or not, and appreciation is shown or not. The subjects felt the emotion they imagined the attended character to be feeling, and the quality of the emotion determined the likelihood of helping. For example, if help is not given in the scenario and subjects were attending to the object, they report sadness and anger. If help is given, subjects attending to the object or the helper report elation (Aderman \& Berkowitz 1969). In another study, 2-year-olds are more aggressive towards peers after observing a simulated conflict between adults (Cummings et al. 1985). The perceptions and responses of the subjects were primed by the observation of aggressive encounters. Such responses can be inhibited or overridden by prosocial responses towards others, but this requires learning (discussed more below).

Of course, the physiology and behavior of the subject are not always going to match that of the object. If there is an appropriate or conditioned response to the state of the object, that response would be more evident than a matching one. For example, human subjects that are empathically concerned show a deceleratory heart-rate response to an object of distress (Eisenberg et al. 1990; $1991 ; 1994)$ and rhesus macaque subjects show increased heart rate to the approach of a dominant animal (controlling for posture and activity) (Aureli et al. 1999).

Following the scope of Lipps' original theory, the Roman Pantheon may impart a sense of weight and solidity, but it also imparts the affordance of shelter and the sense that you can walk through the door. Applied to empathy, perceiving the screaming and flailing of a drowning person may impart fear and a lack of control, but it may also impart the urge to jump in and rescue the person. Imitation emerges much earlier than prosocial response, and people appear to learn to inhibit or control emotional contagion and imitation. Thus, the sense that you are a stone or a distressed person should occur automatically from the perception-action link, while the urge to walk through the door when it's 
raining and jump in the water when one is drowning requires learning. None of these processes need be conscious.

2.1.2.3. Developmental evidence. Infant non-human and human primates are known to respond to the distress of others with distress (e.g. Sagi \& Hoffman 1976; de Waal 1989). Further, newborn humans infants are predisposed to mimic the facial expressions of others (Field et al. 1982; Field et al. 1985; Meltzoff \& Moore 1977; Stern 1977). Human newborns can imitate fear, sadness and surprise (Field et al. 1982), again indicating the importance of communicating distress.

In preschool observations of 25-41 month-olds, the fact that some play interactions were sustained was best explained by the fact that they were initiated with imitation. In a study with toddlers (21-30 months) and preschoolers (31-64 months), toddlers that were friends had greater concordance in the amount of time spent in directing and following/imitating behaviors, parallel play, and requesting (compared to acquaintances). Connecting behavior to physiology, the friend dyads also had a greater concordance in baseline heart rate and cortisol measures. Therefore, similarity even on a physiological level seems to predict friendships characterized by imitative or reciprocal behavior (Goldstein et al. 1989).

Based on extensive research, Meltzoff and colleagues propose the Active Intermodal Mapping Hypothesis (AIM) to explain early facial imitation (Meltzoff \& Moore 1977; 1983; 1994). According to the AIM, the object's expression is perceived and compared to the subject's own current expression (from proprioceptive feedback) in a supramodal representational space. The subject's efferent copy is compared to the object's afferent copy in this space, equivalences are detected and reduced, and imitation results (Meltzoff \& Moore 1997). Our view differs only in the first step. According to the PAM, the perception of the object's expression would automatically activate a similar motor expression in the subject (in contrast to AIM), but through a representation (in agreement with AIM). This expression could in turn be compared through feedback to the representation, and the difference between copies could be detected and reduced (in agreement with AIM).

The infant data suggests that the link between perception and action is strongest initially, and refined through experience. Thus, while perception automatically proceeds to action in infants (through a representation), this progression weakens with age and experience. In an imitation task, attention to the model, general expressivity of the infant, expression correspondence, and accuracy of an observer of the subject to guess the expression of the object decreased from two to three and four to six months (Field et al. 1986). Indicating that imitation is still prominent in subsequent months, children 10- to 14-months old respond to the distress of others with distress expressions that imitate the object (Zahn-Waxler et al. 1977 in Thompson 1987). The researchers suggested that these children were "trying on" the expressions to understand them. Einon and Potegal note that the open display of emotions in 2-year-olds "would be considered pathological in an adult" (1994, p. 189). The authors cannot explain in principle why the intensity of emotions should be so strong in children, especially with family members, but postulate that such temper tantrums are part of the process of learning to control and confine such expressions.

The perception-action link can explain the strength of expression and imitation in children if initially, processing automatically proceeds from perception to activation of the representation to production of the expression or action. Through ontogeny the process could be refined, inhibiting expressions from being produced and differentiating activation generated internally from activation generated by perception of the object. Experimental evidence supports the learned inhibition of expressions through display rules (Cole 1986; Ekman et al. 1969).

As for differentiating the expressions of self from other, the proliferation of experience with selfgenerated motion and causal agency (e.g. Johnson 1987) can create response circuits that are dedicated to, or primed for self-action. For example, activity in the right parietal lobule seems to represent reafferent activation from motor action. Thus, activity in this area could distinguish activity from observing an act in another from self-generated activity. This mechanism is suggested for distinguishing self from other in imitation (Georgieff \& Jeannerod 1998; Iacoboni et al. 1999). Applied to empathy, with an understanding of the way representations change with experience, this mechanism parsimoniously explains differences between and within individuals in the level of empathy expressed since development of self-other differentiation is highly correlated with the 
development of empathy (see Hoffman 1978; Meltzoff 1993; Meltzoff \& Moore 1993) and both are correlated with development of the prefrontal cortex.

In contrast to a declining function of imitation, a study of preschool children aged 24-41 months found a curvilinear relationship, with 3-year-olds exhibiting the greatest amount of imitation of peers during play. But this would not affect the former assumption if one distinguishes between reflexive imitation of expressions/movements and higher-order imitation of emotional or behavioral states. More detailed analyses and future research can discriminate between the trajectories of the two types of imitation.

2.1.2.4. Evidence from empathy disorders. A general "empathy disorder" has been suggested to be a characteristic component of many other disorders including autism, sociopathy, prefrontal damage, fronto-temporal dementia, and even anorexia nervosa. Empathy disorders are characterized by impairments in the conception of mental states, expression of emotions and verbalization of feeling states due to dysfunction in the brain areas that subserve empathy (see Gillberg 1992). The PAM involves a circuit of activity encompassing most of the brain at some level, therefore, no single area needs be responsible for impairments in empathy. The diffuse nature of this circuit explains how many different disorders can result in empathy impairments. Extensive reviews of empathy disorders already exist (e.g. Baron-Cohen et al. 1993; Cohen \& Volkmar 1997; Gillberg 1999; 1992; Prior 1988; Sigman \& Ruskin 1999) thus, only data that shed particular light on the mechanism of empathy are addressed.

As evidence of the importance of the mother-infant relationship for perception-action processes, dyads of depressed mothers and their infants spend a smaller proportion of time matching behavior states than nondepressed dyads (Field et al. 1990). The behavior states and heart rates of the depressed mothers and their infants also cohere less (Field et al. 1989). The fact that depressed dyads match negative behavior states more often than positive (Field et al. 1990) reveals that they are capable of matching behavioral states through the PAM. However, the depressed mothers seem to model positive expressions less; this would impair the ability of the infants to represent positive states, which in turn accounts for impairments in attention, recognition, and imitation of such states. Further, the depressed mothers may spend less time imitating the expressions of the child, which would impair modeling, imitation and general emotion regulation abilities of the child.

By contrast, a disruption in the perception-action link in psychopathic or sociopathic individuals (the terms have been used interchangeably) would account for the characteristic lack of normal autonomic responses to the distress cues of another, the social isolation, and the apparent disregard for the emotional and physical state of others (Aniskiewicz 1979; Blair et al. 1997; House \& Milligan 1976). Moral reasoning is also impaired in sociopathic children, even controlling for cognitive development, IQ, or social class (Blair 1995; 1997; Blair et al. 1997; Campagna \& Harter 1975). Without the ability to be aroused by the distress of others, these individuals cannot understand and learn about the state of others through their own substrates. Providing a sense of continuity, psychopathy also appears to be a relevant dimension for personality in animals, namely chimpanzees and dogs (Lilienfeld et al. 1999).

Focal prefrontal cortex damage and closed-head injury in adults result in changes in empathy (reviewed by Eslinger 1998). Patients with early-onset damage to the prefrontal cortex have a syndrome resembling psychopathy, with little or no empathy or remorse, a paucity of lasting social relationships, significant impairments on moral reasoning despite normal performance on intellectual tasks, and a deficient increase skin conductance response to risk in a gambling task (Anderson et al. 1999). One of the two subjects with early prefrontal damage was a mother marked by "dangerous insensitivity to the infants needs" (Anderson et al 1999, p. 1032). The authors propose a mechanism for the disorder whereby brain damage prevents patients from developing knowledge of the emotional aspects required for navigating and understanding social situations. Relevant to the PAM, patients with prefrontal lesions exhibit compulsive imitation of gestures and complex actions in the laboratory (Lhermitte et al. 1986). This supports the strength of the PAM and indicates that normally, the prefrontal cortex inhibits the processing of perception to action. This is one of the bases for assuming that the PAM can link emotional contagion to cognitive empathy (discussed below).

Empathy impairments in sociopathy and autism are also thought to be partially due to a disruption in the prefrontal system because both involve deficiencies on tasks requiring inhibition, planning, and 
attention (Campagna \& Harter 1975; Dawson 1996; Gillberg 1999). However, because expression, imitation, and recognition of expressions and gestures are impaired in individuals with autism, it is likely that the disorder is characterized by an impairment early on in the perception-action pathway (described below).

Deficits in autism exist on the same processes required for development of empathy in normallydeveloping individuals (above). Infants with autism lack the coordination of activity with their caregiver suggested to regulate and organize emotions (e.g. Brazelton et al. 1974, Deboer 1979; Gable \& Isabella 1992; Levine 1990; Stern 1974; 1977). They are less likely than normal children to smile in response to smiles from their mother and less likely to combine eye contact with smiles (Dawson et al. 1990; Kasari et al. 1990). 20 month-old infants do not attempt to engage the attention of an adult in response to an ambiguous object or situation, do not respond with affect and attention to the live distress of an adult, and are impaired at imitation (Charman et al. 1997). Later in childhood, similar tasks also show a diminished response to other's distress (Dawson et al. 1990; Kasari et al. 1990; Loveland \& Tunali 1991; Sigman et al. 1992). Older children with autism do not use joint attention or gestures to share mental experiences with others (Baron-Cohen 1989; 1995; Kasari et al. 1990; Mundy et al. 1986; Sigman et al. 1986), though they can direct their own and the attention of others to obtain and convey information (Charman et al. 1997; for a review see Mundy et al. 1994). Children with autism do not report feeling the same emotion as a protagonist on a videotape (Yirmiya et al. 1992). Skin conductance measures of autistic and normal children show higher responses to color slides of distress and threatening objects than to neutral stimuli and some autistic subjects spontaneously report an aversive response to distress slides, but the autistic children had significantly lower responses to threatening objects than normals (Blair 1999).

The spontaneous expressions of individuals with autism are more neutral and idiosyncratic than comparison subjects, described as including "bizarre", "mechanical", or "incongruous" aspects (Loveland et al 1994; Ricks 1979; Yirmiya et al. 1989). They display less positive affect than comparison individuals, especially the vicarious form (Dawson et al. 1990). They have difficulty recognizing emotional expression in the body (Hobson 1993; Hobson et al. 1989), and the face (Bormann-Kischkel et al. 1995; Capps et al. 1992; Hobson et al. 1989; Macdonald et al. 1989; Tantam 1989, but see Ozonoff et al. 1990 and Prior et al. 1990). There are also impairments on matching different but corresponding aspects of emotional expression such as facial expression and vocal affect (Hobson 1986a; 1986b; Hobson et al. 1988; 1989; Loveland et al. 1995). Some believe, however, that their deficit is restricted to complex emotions such as surprise and embarrassment (Baron-Cohen 1993; Bormann-Kischkel et al. 1995; Capps et al. 1992). Children with autism also show impairments imitating body movements (particularly unfamiliar ones), actions on objects, and gestures (particularly facial) (Curcio 1978; DeMyer et al. 1972; Jones \& Prior 1985; Ohta 1987). However, basic-level gestural and procedural imitation may be intact in school-age children with autism (Charman \& Baron-Cohen 1994; Morgan et al. 1989).

A high-functioning autistic adult reports that although he has difficulty understanding or participating in social interactions, he puts great effort towards such interactions and as a result has formed meaningful relationships (Cesaroni and Garber 1991). Indeed the data suggest that individuals with autism have emotional reactions to their environment and the people in them, but the quality of their experience is different. Individuals with autism have been responsive and playful in some laboratory interactions, show positive and negative emotions like comparison groups, and form attachment relationships (for a review see Capps \& Sigman 1996). They show autonomic reactions to the distress of others, but may be less likely to attend to this distress and/or have a matching physiological response, reducing the possibility of an accurate behavioral response.

Theories about the neurological nature of the disorder implicate the cerebello-frontal pathway. Twelve out of 12 cerebellum samples from individuals with autism showed decreased purkinje cell counts in the vermis and hemispheres of the cerebellum. On average, cells in the cerebellum were reduced by $30-50 \%$, in one case 95\%. Imaging data shows that individuals with autism have smaller cerebellums than normally-developing individuals, evident from before the first year and persisting throughout life. As further evidence, the decrease cerebellar size from MRI analysis is correlated with the degree of slowed orienting in children with autism (Harris et al. 1999).

The cerebellum is thought to be important in motor and cognitive tasks that require subjects to coordinate physical and mental activities with external stimuli, including social and emotional 
processes (see Courchesne 1997). It is required for stimulus-driven motor behavior and feeds heavily to the frontal cortex. Thus, autism may result from an abnormality that precludes forming the normal links between perception and action, perhaps at the level of orienting attention to the relevant stimuli. Given the importance of orienting and joint attention processes in emotional development, individuals with autism are doubly impaired because the inability to gather information from the environment compromises their ability to learn shared affect and to develop emotion regulation, both of which are necessary for empathy and theory of mind.

The role of attention in empathy is supported by behavioral data from individuals with autism. These subjects perform better on tasks in the laboratory than in more naturalistic settings, possibly because there are fewer distractions in the laboratory and response time is not limited (Capps \& Sigman 1996; Gillberg 1999). Children with autism are only impaired on social perception tasks when there is more than one cue, suggesting that their impairment on orienting, disengaging and selecting targets for attention underlies the general social deficits (Gillberg 1999). In cognitive tasks, children with autism tend to focus on local-level, isolated stimuli, rather than global-level, contextualized stimuli; normally developing children and developmentally-delayed children without autism tend towards the reverse (Frith 1989).

In conclusion, the varied types of empathy disorders support the idea that empathy is a neurologically-distributed process. Empathy disorders are most severe in individuals who have problems from infancy. The specific impairments of individuals with empathy disorders support the need for an innate orientation towards socio-emotional stimuli. Without that, emotional development in general will be impaired, precluding empathy. For proper development, social-emotion interest must also be met with behavioral responsiveness and coordination by the caregiver. Many PAMrelated processes seem to rely on this unfolding of events, including lower level behavioral processes like imitation, expression production and expression recognition.

\subsection{Representation as a Common Denominator}

As mentioned in the introduction, the most robust effects in empathy experiments can broadly be categorized as effects of familiarity/similarity, past experience, learning (explicit and implicit) and cue salience. The former three effects can be explained by the PAM because they inherently rely on representations; the last because it differentially activates representations. Applying the perceptionaction hypothesis to emotional behavior, the representations of the subject can map the meaning of expressions, not just body postures and facial expressions. Because our PAM of empathy requires representations affected by learning and experience; it is also consistent with learning or conceptual development theories of empathy.

2.2.1. Representations change with experience. The effects of familiarity, similarity, past experience, and learning have been addressed as separate variables due to the slightly different emphasis of each discipline. Learning, for example, is more relevant to developmental studies, because these studies focus on the role of rearing on individual differences. Past experience is more applicable to animal studies because of its role in determining a subject's response to an unconditioned stimulus. However, all of these effects result from the ability of the nervous system to create and refine representations through experience.

In his famous essay, "What is it like to be a bat?", Nagel postulates that the "objective ascription of experience is possible only for someone sufficiently similar to the object of ascription to be able to adopt his point of view...the more different from oneself the other experiencer is, the less success one can expect with this enterprise" (Nagel 1974, p.442). Similarly, Titchener thought that through empathy, one could understand individuals of intellectual and moral similarity (1915, in Wispé 1987). Hume noted that it is easier to sympathize with someone if you have something in common with that person (1888/1990). According to Freud, "everything that establishes significant points in common between people arouses such fellow feelings, such identifications" (Freud 1950, p.83). These theorists all touch on the extent to which familiarity and similarity facilitate empathy and perspective taking.

The greater the familiarity or similarity, the richer the subject's representation of the object. A rich representation involves more associations, and thus creates a more complex, elaborated and accurate pattern of activity in the subject, a pattern encoded with reference both to personal experience and 
experience with the object. For example, when one perceives the distress of a loved one, the subject's own representation of distress will be activated by the facial, body and vocal expressions of distress, common to the object and subject. Importantly, the representation of the loved one will also be activated. This representation has been created over many, many interactions, across many situations and thus includes associations to previous instances of distress in the object, the object's attitude towards the situation, the long-term consequences the distress will have on the object, etc. Thus, the distress of the subject will be greater upon perceiving distress in a familiar or similar individual because the ability to elaborate on the distress is greater. In addition, because of the perception-action link, extended interactions between the subject and object will tend to alter their means of expression to be more similar. This results in a more ready mapping of perception to action, and thus better understanding.

The richness of the representation also entails that the subject's ability to perceive the state of the object will be less affected by noise in the signal. If a subject's representation of a close friend is very rich, it allows the subject to recognize the friend from further away, in less clear conditions, and with a shorter exposure time than an acquaintance. Applied to empathy, a richer representation allows the subject to perceive the state of the object more quickly, from more subtle cues, and in more ambiguous situations. Although, given longer to decide, a subject can surely apply conscious cognitive processes to interpret the state of an unfamiliar object.

At the most basic level, the PAM requires the subject and object be at least familiar or similar enough to allow for direct perception. The prototype theory of categorization (e.g. Rosch 1973; 1988; Rosch $\&$ Mervis 1975) predicts that the strength of the activation of a representation is proportional to the degree of overlap between the input and the representation (McClelland \& Rumelhart 1985). A robin activates the bird representation more strongly than a penguin because the former has more overlap with the prototype representation. Applying the PAM, the sight of a primate moving a forelimb would more strongly activate a human's representation than the sight of a rodent. In turn, a rodent would activate the representation more than a reptile. The morphology and biomechanics of the movement overlap more in the former cases and thus activate the representation more strongly.

The extent to which animals empathize with members of their own and other species can be attributed to differences in morphology and biomechanics (as also noted by Hume 1888/1990). For example, monkeys experimentally conditioned to react to the object's distress (described above) did not respond to the shock of an albino rat or the simulated distress of a monkey-like puppet. Much comparative data notes the need for stimuli to be naturalistic or multi-modal to evoke a response (e.g. Lavery \& Foley 1963; Miller et al. 1959; Partan \& Marler 1999; Preston \& Jacobs in press); responses should be proportional to the extent of overlap between the stimulus and the representation. Similarly, increased experience is thought necessary for empathy towards differenly-abled objects. For example, through learning, non-human primates can extend increased tolerance towards handicapped individuals. Two chimpanzee juveniles housed with an injured female "scrupulously avoided disturbing [the female]...now and then one or the other would go to her and touch her gently or caress her" (Yerkes \& Yerkes 1929, p. 297). Even aggressive macaque species treat handicapped individuals with more tolerance than normally-developing individuals (de Waal et al. 1996). Experience can refine the subject's representation, promoting tolerance and help tailored to the object's needs.

A refined representation may also explain how empathy can be extended across species, despite morphological differences. For example, in home tests of empathy with children, the family pet often responds with consolation to the adult feigning distress (Zahn-Waxler et al. 1984). Lucy, a chimpanzee raised by a human family is described as exhibiting efforts to break up conflicts, running to comfort the wife when ill, exhibiting "protectiveness toward her, bringing her food, sharing her own food, or... attempting to comfort by stroking and grooming her" (Temerlin 1975, p. 165). There are also anecdotal reports of apes helping unfamiliar birds and humans, sometimes even incurring great risk to do so (e.g. O'Connell 1995; de Waal 1997b). Taken together, the examples support the ability of familiarity to supplant absolute similarity, perhaps at a level beyond morphology and biomechanics that also involves emotional attachment.

From 9-12 months, children prefer to play with children of the same age and sex (Smith 1988). In an experiment with preadolescent boys, subjects imitated the actions of a model when playing a war strategy game more when manipulated to feel similar to the model (Rosekrans 1967). The PAM 
assumes that children prefer playmates that are similar because they can better map the behavior of these individuals onto their own representations, allowing for successful understanding, prediction and coordination in play.

Past experience effects can also be explained by the same principles as familiarity/similarity. If a subject needs to access representations of a particular internal state to understand the object's situation, then one would expect more empathizing for situations or states that the subject has experienced. For example, in the comparative empathy experiments, previous experience with shock greatly facilitated empathic responding. Subjects who were shocked previously would have mapped the perception of a conspecific in a familiar situation onto their own representation of pain reactions, activating the associated distress. After experiencing shock, subjects had richer representations of this event and their representations were directly associated with autonomic consequences. Of course, when shock to the subject is conditioned to that of the object, the subject simply fears the CS (shock to the object) because it preceded the UCS (shock to the subject), consistent with Church's (1959) and Allport's (1924) model.

The "affective congruency effect" of the attention and social cognition literatures indicates that being in a similar state to another facilitates attention, processing and memory for the event. Subjects respond more quickly to targets that are affectively congruent with the priming stimuli. Congruous states may be more easily processed due to priming and spread of activation (e.g. see Bower et al. 1981; Singer \& Salovey 1988; Spizzichino \& Bonaiuto 1990) or due to the response interference that primes create for distractors (Wentura 1999). Either way, affective congruence predicts that individuals who are primed for the situation or emotion of the object will be more aroused, will engage in more perspective taking and will exhibit more empathy than a non-primed subject.

These mechanisms would hold throughout the life span. Thus, a correlation should exist between the scope of the subject's life experience and the scope of situations in which the subject responds appropriately (as in Hoffman 1990). Beyond effects of experience, advanced cognitive capabilities of adult humans would facilitate cognitive perspective taking that is not stimulus driven (addressed in the cognitive empathy section below).

2.2.2. Representations and cue salience. The refinement of representations through experience was able to parsimoniously explain three of the four major effects in the empathy literature. The final effect, cue salience, is related because of its ability to increase the likelihood and extent to which a representation is activated. Salience is inherently tied to the level of attention the subject pays to the object; the more salient an event, the more likely it will be attended to (Colby \& Goldberg 1999; Taylor \& Stein 1999), providing the opportunity for empathy. Objects and situations that are perceptually loud, include releasing stimuli (like crying or screaming), or are familiar to the subject will be most salient.

Salience also increases the likelihood of imitation through attention. In infants, the perception-action link is still strong and less inhibited, therefore, if an infant is attending to a stimulus, imitation should take place. As evidence, attention towards and imitation of a model both decrease between 2 and 6 months (Field et al. 1986). When observed actions are particularly salient, a brief, truncated version of the movement is produced (pers. com. from L. Fadiga, in Rizzolatti and Arbib 1998), called an "ideo-motor action" (cf. Carpenter 1874, Eisenberg \& Strayer 1987; James 1890; Lotze 1852; Prinz 1987). Thus, attention may reduce learned inhibition, allowing a reduced version of the movement to "leak out". In this way, the PAM can replace cognitive perspective-taking explanations for such effects, parsimoniously linking the mechanism for these effects with infant imitation, emotional contagion, empathy and helping.

\section{An explanatory theory}

Applying the PAM and the role of representations to empathy, we hypothesize that empathic understanding comes when the subject's own representation of the emotion or situation is directly activated by perception of the object's. The representations activated in the subject in turn activate physiological and behavioral responses that are processed to the response phase unless inhibited. These responses are most obvious in ideo-motor actions, reflexive imitation, and emotional contagion, and prevail in phylogeny and ontogeny until prefrontal cortical functioning is sufficient to inhibit the response or the subject maps the representation onto an object-oriented response. 
If we assume that the brain is wired to understand the behavior of others through egocentric representations and through the individual's own substrates of emotion, then general empathic processing proceeds as follows: the subject directs attention to the distress of the object, the limbic system and cortical representations of the object, the situation and emotion are activated. The extent of activation determines the extent that processing proceeds to action. If processing is not deep enough or elaborated enough, the subject will not be involved in the state of the object and helping is unlikely, especially with highly familiar objects. If processing is a little deeper, the relevant limbic and cortical areas will be more strongly activated, the subject will be involved in the state of the object, will experience empathy and is likely to help. If processing proceeds even further towards action, the subject will also experience distress, and will increasingly help his or herself rather than the object.

In addition to depth of processing, the level of response is commensurate with the level of inhibition. Adults normally inhibit imitation during the observation of an action, either centrally (from prefrontal inhibition), peripherally (with spinal cord inhibition blocking the motorneurons that execute the action), or both. The compulsive imitation of gestures and complex acts by patients with prefrontal lesions supports the role of the prefrontal cortex in inhibition (Lhermitte et al. 1986). Thus, the extent of inhibition also determines the level of contagion or imitation in the subject.

There are some additional entailments of the PAM that should be made explicit. Although empathy involves a subject who develops a similar emotional state to the object, it does not require that the subject feel the exact same subjective emotion as the object. Cognitive appraisal of the situation (e.g. Frijda 1993; Lazarus 1991) associations based on past experience, autonomic stimulation and subsequent feedback (e.g. James 1884; Tomkins 1962) all contribute to subjective experience, but would not necessarily be the same for the subject and object.

In addition, existing representations shape the subject's perception as much as perceptions shape representations. Thus Hume noted, "There is a very remarkable inclination in human nature, to bestow on external objects the same emotions, which it observes in itself; and to find every where those ideas, which are most present to it" (1888/1990; p. 224). Similarly, a high-functioning autistic adult challenged current theories of empathy, concluding that empathy is only less likely between himself and others because his projections do not match their perceptions and vice versa (Cesaroni \& Garber 1991). He states: "It is...much easier to empathize with someone whose ways of experiencing the world are similar to one's own than to understand someone whose perceptions are very different" (p. 311). Human interpretations of animal behavior are also criticized for resulting from projection more than perception (see Mitchell et al. 1997).

Projection is thought to be inconsistent with empathy, because the mapping goes from subject to object rather than object to subject (Eisenberg \& Strayer 1987); but projective ideas of empathy are explainable by the PAM since perception and understanding require activation of one's own representations, and one's own representations are more likely to be more applicable to the subject than the object. Through experience with the object, subjects can fine-tune representations of the object, increasing the likelihood of an object-appropriate interpretation. But focusing on the objectappropriate representations requires cognitive effort, again a function of the prefrontal cortex.

3.1. Cognitive empathy and perspective taking. As mentioned in the introduction, cognitive empathy theories conceive of empathy as a perspective-taking process where one uses something like imagination or projection to put oneself in the place of the object. This process then affords traditional PT, deception, active teaching, empathy and helping behaviors. But a strong PT view of empathy undermines the continuity between emotional contagion and cognitive empathy.

If the continuity of emotional contagion and empathy is emphasized, then cognitive development (through phylogeny or ontogeny) could allow the subject to distinguish distress directly caused by personal insult from distress caused indirectly by insult to the object. According to this view, cognitively "advanced" individuals can use inference, causal reasoning and a refined distinction between self and other to determine the source of distress. If a state was activated by that of the object, the subject can avoid personal distress by inhibiting attention to the distress, inhibiting expression of the distress and inhibiting elaborative processes - processes that normally augment personal distress. Thus, through experience, an individual can causally locate the source of distress and control the extent of personal distress. 
Altricial species with a protracted learning period and larger prefrontal cortex will have more advanced empathy skills for many reasons. Their protracted development will provide them with a larger base of knowledge of individuals and situations. This allows individuals to better predict and understand the situations that cause distress in particular people, and what helps to assuage the distress. An increase in working memory provides a larger capacity to hold the information in order to predict, compare possible outcomes, and decide on a course of action. The increase in inhibitory control associated with prefrontal development can decrease the amount of imitation or personal distress, even in the face of cognitive elaboration required by the former processes. The PAM gave evidence that imagination activates the same representations as behavior and perception. Thus, imaginative capabilities allow individuals to evoke empathic processes and responses in the absence of direct stimulation from an object of distress. Taken together, an increase in prefrontal functions alone can account for increases in the effectiveness of empathy by helping the subject to focus on the object, even in it's absence, remain emotionally distinct from the object, and determine the best course of action for the object's needs.

Higher cognitive faculties can also augment helping behaviors through explicit teaching. In human children, direct instruction, reasoning, discipline, and reinforcement of helping are necessary for prosocial competence (Eisenberg et al. 1983; Radke-Yarrow 1983; Ungerer 1990; Zahn-Waxler et al. 1984). These explicit factors can either push a below-threshold state of empathy into an act of helping or subvert empathy altogether when it is required by social rules, but not naturally evoked.

\section{Final comments and future research}

Data suggest that empathy is a phylogenetically-continuous ability based in group living and extended care-giving that has been extended through the extension of cognitive abilities to be applicable to nonkin and beyond the scope of one's own experience. Prevalent historical ideas about the mechanism of empathy is gaining credence from recent trends in neuroscience that show perception and action to share a common representational code. According to the perception-action view, perceiving an event, be it another person reaching for a cup or crying over the loss of a loved-one, activates some of the same circuits used when performing the actions. Taking a perception-action model (PAM) of empathy seriously and augmenting it with details regarding the nature of the representations and prefrontal functioning allows us to finally combine previously disparate theories of empathy.

The fact that perception proceeds automatically to action explains emotional contagion, imitation, and ideo-motor responses. The fact that perception and action share stored representations that change with experience explains the fact that emotional and empathic responses can be conditioned by experience. With respect to cognitive empathy, there are multiple overlapping factors that explain its emergence from emotional contagion and imitation. Prefrontal activity can inhibit responses from being generated, and increase the extent to which subjects can control and direct attention and distress to the object. Moreover, because imagination activates the shared representations of perception and action, individuals with sufficient working memory and inhibitory control can generate empathic responses in the absence of an object. Thus, augmenting the perception-action link with prefrontal capacities can account for differences across species and stages of development in the level of empathy achievable.

There are some aspects that are not yet clear from our model. For example, neurological evidence will have to elucidate the extent to which "a shared representation for perception and action " should be taken literally. For example, the brain's representation of a particular individual does not need to exist at one location in cortex with inputs coming in from sensory processing areas, and out to motor. It may be more accurate to say that information processed by sensory systems activates "hot spots" that were previously associated with the stimulus, tuned to the same frequencies etc., and that these patterns of activation automatically proceed to response phases unless inhibited. Future neuroanatomy and neurophysiology work can correlate the properties of the perception-action with behavioral levels of empathy across species and can differentiate between automatically prepared responses that are imitative and those geared towards response properties of the stimulus.

Future research must address the possible primary role of the allocation of attention in mediating the evocation of empathy. It is probable that people selectively inhibit attention to avoid being emotionally drawn into situations that with a high cost/benefit ratio. This can be tested with negative priming 
paradigms whereby reaction times assay the extent of inhibition (response times to previouslyinhibited locations are much longer) (Tipper 1985; Tipper \& Cranston 1985). For example, it should take longer to identify previously seen items that inhibit empathic attention (like a homeless beggar), than neutral stimuli or releasing stimuli (like a child or a puppy).

Future research could also investigate the role that attention plays in phenomena like guilt and denial. In orienting studies with infants, even though overt distress can be decreased by distracting or reorienting attention, distress returns to almost equal levels when the distraction stimulus is removed, and the hormonal stress response may remain throughout (Harman 1994; Gunnar et al. 1984; reviewed in Rothbart et al. 1994). This internal "distress keeper" (Rothbart et al. 1994) may be the mechanism for negative feelings like guilt that pervade even when attention is shifted away from a distressing stimulus. As evidence, trait sympathy is correlated with the probability for entering situations of distress and the susceptibility for guilt and shame after refusing to help (reviewed by Smith 1992).

The proximate model can also be used as a working hypothesis to understand disorders of empathy such as autism, psychopathy and fronto-temporal dementia (FTD). One must think of empathy as a process that begins with attention, proceeds to representation and then to action. The overlapping stages in the perception-action link can be tested sequentially to determine the locus of impairment, beginning with attention, then testing imitation, emotional contagion, empathy, and cognitive empathy. For example, research on individuals with autism reveals general attentional impairments, which may preclude the perception, production and imitation of expressions and gestures, as well as more cognitive tasks like theory of mind. Psychopathy, on the other hand, lacks physiological responses to others distress; therefore, the emotional linkage with others is defective, precluding emotional contagion, empathy or cognitive empathy. Again, with this model, empathy is not a modular capability, circumscribed to a location in the brain. Rather, it is a process made possible by the general way the brain processes all types of information. When this process is utilized for processing emotional information, emotional contagion, empathy, and cognitive empathy result. It is an adaptive structure that allows individuals to use the same tissue for representing self-action and understanding the actions of others, in both cases, facilitating a response from input.

Returning for a moment to evolution and function, the complex social world of primates requires the central nervous system to perceive the facial expressions, body postures, gestures, and voices of conspecifics accurately and quickly in order to generate a response (Brothers 1990; Byrne \& Whiten 1988). Parsimoniously, the same nervous system link between perception and action that helps us to navigate the physical environment helps us navigate the social environment. The perception-action link allows for facile motor skill acquisition as well as facile social interaction, as we perceive external conditions and incorporate them into our current plan of action. In this way, the proximate model is intricately linked with the ultimate model. While natural selection acts on phenotypes, these phenotypes express underlying physiology. Thus, the general design of the nervous system, created through millions of years of evolution, should be considered a factor in the evolution of emotional processes like empathy and overt behaviors like helping. In this way, one can see how intimately related the ultimate and proximate levels can be.

\section{ACKNOWLEDGMENTS}

The authors would like to thank the following people for reading and giving helpful comments on previous versions: Filippo Aureli, Rachel Ebling, Lisa Parr, Jose Soto, Brent Stansfield, and Frank Sulloway. Stephanie Preston would also like to thank Brent Stansfield for his pervasive patience and assistance and for creating Figure 1.

\section{References}

Acebo, C. \& Thoman, E. B. (1992) Crying as social behavior. Infant Mental Health Journal 13:6782.

Aderman, D. \& Berkowitz, L. (1969) Empathy, outcome, and altruism. Paper presented at the Proceedings from the 77th Annual APA Convention. 
Adolphs, R. (1999) Social cognition and the human brain. Trends in Cognitive Sciences 3:469-479.

Adolphs, R., Cahill, L., Schul, R. \& Babinsky, R. (1997) Impaired declarative memory for emotional material following bilateral amygdala damage in humans. Learning \& Memory 4:291-300.

Adolphs, R., Damasio, H., Tranel, D., Cooper, G. \& Damasio, A. R. (2000) A role for somatosensory cortices in the visual recognition of emotion as revealed by three-dimensional lesion mapping. Journal of Neuroscience 20:2683-2690.

Adolphs, R., Tranel, D., Damasio, H. \& Damasio, A. (1994) Impaired recognition of emotion in facial expressions following bilateral damage to the human amygdala. Nature 372:669-672.

Allport, A. (1987) Selection for action: Some behaviorial and neurophysiological considerations of attention and action. In: Perspectives on perception and action, ed. H. Heuer \& A. F. Sanders.

Lawrence Erlbaum Associates, Inc.

Allport, F. H. (1924) Social Psychology. The Riverside Press.

Allport, G. (1961) Pattern and Growth in Personality. Holt, Rinehart \& Winston.

Allport, G. (1968) The historical background of modern social psychology. In: Handbook of Social Psychology, ed. G. Lindzey \& E. Aronson. Addison-Wesley.

Allport, G. W. (1937) Personality; a psychological interpretation. Henry Holt.

Anderson, S. W., Bechara, A., Damasio, H., Tranel, D., \& \& Damasio, A., R. (1999) Impairment of social and moral behavior related to early damage in human prefrontal cortex. Nature Neuroscience 2:1032-1037.

Aronfreed, J. (1968) Conduct and Conscience. Academic Press.

Aureli, F., Das, M. \& Veenema, H. C. (1992) Interspecific differences in the effect of kinship on reconciliation frequency in macaques. Abstracts of the 30th Annual Meeting of the Animal Behavior Society:5.

Aureli, F., Preston, S. D. \& de Waal, F. B. M. (1999) Heart rate responses to social interactions in free-moving rhesus macaques (Macaca mulatta): A pilot study. Journal of Comparative Psychology 113:59-65.

Aureli, F., van Schaik, C. P. \& van Hooff, J. A. R. A. M. (1989) Functional aspects of reconciliation among captive long-tailed macaques (Macaca fascicularis). American Journal of Primatology 19:39-51.

Baron-Cohen, S. (1989) Perceptual role taking and protodeclarative pointing in autism. British Journal of Developmental Psychology 7:113-127.

Baron-Cohen, S. (1993) From attention-goal psychology to belief-desire psychology: The development of a theory of mind and its dysfunction. In: Understanding other minds: Perspectives from autism, ed. S. Baron-Cohen, H. Tager-Flusberg, \& D. Cohen. Oxford University Press.

Baron-Cohen, S. (1995) Mindblindness: An essay on autism and theory of mind. The Mit Press.

Baron-Cohen, S., Tager-Flusberg, H. \& Cohen, D. (eds.). (1993) Understanding other minds: Perspectives from autism. Oxford University Press.

Batson, C. D., Duncan, B. D., Ackerman, P., Buckley, T., \& \& Birch, K. (1981) Is empathic emotion a source of altruistic motivation? Journal of Personality and Social Psychology 40:290-302.

Batson, C. D., Fultz, J. \& Schoenrade, P. A. (1987) Distress and empathy: Two qualitatively distinct vicarious emotions with different motivational consequences. Journal of Personality 55:19-39. 
Becker, H. (1931) Some forms of sympathy: a phenomenological analysis. Journal of Abnormal \& Social Psychology 26:58-68.

Bell, R. Q. (1968) A reinterpretation of direction of effects in socialization. Psychological Review 75:81-95.

Bell, R. Q. (1971) Stimulus control of parent or caretaker behavior by offspring. Developmental Psychology 4:63-72.

Bell, S. M. \& Ainsworth, M. D. (1972) Infant crying and maternal responsiveness. Child Development 43:1171-1190.

Bemporad, J. R., Ratey, J. J. \& O'Driscoll, G. (1987) Autism and emotion: An ethological theory. American Journal of Orthopsychiatry 57:477-484.

Blair, R. J. R. (1995) A cognitive developmental approach to morality: Investigating the psychopath. Cognition 57:1-29.

Blair, R. J. R. (1997) Moral reasoning and the child with psychopathic tendencies. Personality \& Individual Differences 22:731-739.

Blair, R. J. R. (1999) Psychophysiological responsiveness to the distress of others in children with autism. Personality \& Individual Differences 26:477-485.

Boodin, J. E. (1921) Sensation, imagination and consciousness. Psychological Review 28:425-453.

Bormann-Kischkel, C., Vilsmeier, M. \& Baude, B. (1995) The development of emotional concepts in autism. Journal of Child Psychology \& Psychiatry \& Allied Disciplines 36:1243-1259.

Bower, G. H., Gilligan, S. G. \& Monteiro, K. P. (1981) Selectivity of learning caused by affective states. Journal of Experimental Psychology: General 110:451-473.

Bowlby, J. (1958) The nature of the child's tie to his mother. International Journal of PsychoAnalysis 39:350-373.

Bowlby, J. (1969) Attachment. Basic Books.

Brazelton, T. B., Koslowski, B. \& Main, M. (1974) The origins of reciprocity: The early motherinfant interaction. In: The effect of the infant on its caregiver, ed. M. Lewis \& L. Rosenblum. Wiley.

Brothers, L. (1990) The neural basis of primate social communication. Motivation \& Emotion 14:8191.

Buchheimer, A. (1963) The development of ideas about empathy. Journal of Counseling Psychology 10:61-70.

Byrne, R. W. \& Whiten, A. (eds.). (1988) Machiavellian intelligence: Social expertise and the evolution of intellect in monkeys, apes, and humans. Clarendon Press/Oxford University Press.

Campagna, A. F. \& Harter, S. (1975) Moral judgement in sociopathic and normal children. Journal of Personality and Social Psychology 31:199-205.

Campos, J. B., K.; Lamb, M.; Goldsmith, H.; Sternberg, C. (1983) Socioemotional development. In: Handbook of child psychology: Volume 2. Infancy and developmental psychology., ed. P. H. Mussen. Wiley.

Canli, T., Desmond, J. E., Zhao, Z., Glover, G. \& Gabrieli, J. D. E. (1998) Hemispheric asymmetry for emotional stimuli detected with fMRI. Neuroreport 9:3233-3239. 
Capps, L. \& Sigman, M. (1996) Autistic aloneness. Emotion: Interdisciplinary perspectives.:273296.

Capps, L., Yirmiya, N. \& Sigman, M. (1992) Understanding of simple and complex emotions in non-retarded children with autism. Journal of Child Psychology \& Psychiatry \& Allied Disciplines 33:1169-1182.

Carpenter, W. B. (1874) Principles of mental physiology, with their applications to the training and discipline of the mind and the study of its morbid conditions. Appleton.

Cesaroni, L. \& Garber, M. (1991) Exploring the experience of autism through firsthand accounts. Journal of Autism \& Developmental Disorders 21:303-313.

Charman, T. \& Baron-Cohen, S. (1994) Another look at imitation in autism. Development \& Psychopathology 6:403-413.

Charman, T., Swettenham, J., Baron-Cohen, S., Cox, A., Baird, G. \& Drew, A. (1997) Infants with autism: An investigation of empathy, pretend play, joint attention, and imitation. Developmental Psychology 33:781-789.

Cheney, D. L. \& Seyfarth, R. M. (1985) Vervet monkey alarm calls: Manipulation through shared information? Behaviour 94:150-166.

Church, R. M. (1959) Emotional reactions of rats to the pain of others. Journal of Comparative \& Physiological Psychology 52:132-134.

Cialdini, R. B., Brown, S. L., Lewis, B. P., Luce, C. \& Neuberg, S. L. (1997) Reinterpreting the empathy-altruism relationship: When one into one equals oneness. Journal of Personality and Social Psychology 73:481-494.

Cohen, D. J. \& Volkmar, F. R. (eds.). (1997) Handbook of autism and pervasive developmental disorders. J. Wiley.

Cole, P. (1986) Children's spontaneous control of facial expression. Child Development 57:13091321.

Cook, N. D., Frnh, H., Mehr, A., Regard, M. \& Landis, T. (1994) Hemispheric cooperation in visuospatial rotations: Evidence for a manipulation role for the left hemisphere and a reference role for the right hemisphere. Brain and Cognition 25:240-249.

Cords, M. \& Thurnheer, S. (1993) Reconciling with valuable partners by long-tailed macaques. Ethology 93:315-325.

Corodimas, K. P. \& LeDoux, J. E. (1995) Disruptive effects of posttraining perirhinal cortex lesions on conditioned fear: Contributions of contextual cues. Behavioral Neuroscience 109:613-619.

Courchesne, E. (1997) Brainstem, cerebellar and limbic neuroanatomical abnormalities in autism. Current Opinion in Neurobiology 7:269-278.

Craighero, L., Fadiga, L., Rizzolatti, G. \& Umilta, C. (1998) Visuomotor priming. Visual Cognition 5:109-125.

Cummings, E. M., Iannotti, R. J. \& Zahn-Waxler, C. (1985) Influence of conflict between adults on the emotions and aggression of young children. Developmental Psychology 21:495-507.

Darwin, C. (1871/1982) The descent of man, and selection in relation to sex. Princeton University Press.

Darwin, C. (1998/1872) The expression of the emotions in man and animals. Oxford University Press Inc. 
Davidson, R. J. \& Ehrlichman, H. (1980) Lateralized cognitive processes and the electroencephalogram. Science 207:1005-1006.

Dawson, G. (1996) Brief report: Neuropsychology of autism: A report on the state of the science. Journal of Autism and Developmental Disorders 26:179-184.

Dawson, G., Hill, D., Spencer, A., Galpert, L. \& Watson, L. (1990) Affective exchanges between young autistic children and their mothers. Journal of Abnormal Child Psychology 18:335-345.

Deboer, M. M. \& Boxer, A. M. (1979) Signal functions of infant facial expression and gaze direction during mother-infant face-to-face play. Child Development 50:1215-1218.

Decety, J., Grezes, J., Costes, N., Perani, D., Jeannerod, M., Procyk, E., Grassi, F. \& Fazio, F. (1997) Brain activity during observation of actions: Influence of action content and subject's strategy. Brain 120:1763-1777.

Decety, J. \& Jeannerod, M. (1995) Mentally simulated movements in virtual reality: Does Fitts's law hold in motor imagery? Behavioural Brain Research 72:127-134.

Demaria, C. \& Thierry, B. (1992) The ability to reconcile in Tonkean and rhesus macaques. Abstracts of the 30th Annual Meeting of the Animal Behavior Society:101.

Demos, V. (1984) Empathy and affect: Reflections on infant experience. In: Empathy II, ed. J. Lichtenberg, M. Bornstein, \& D. Silver. Analytic Press: Distributed by L. Erlbaum Associates.

DeMyer, M. K., Alpern, G. D., Barton, S., DeMyer, W. E., Churchill, D. W., Hingtgen, J. H., Bryson, C. Q., Pontius, W. \& Kimberlin, C. (1972) Imitation in autistic, early schizophrenic and non-psychotic subnormal children. Journal of Autism and Childhood Schizophrenia 2:264-287.

Dennett, D. C. (1988) The intentional stance in theory and practice. In: Machiavellian Intelligence: Social expertise and the evolution of intellect in monkeys, apes, and humans, ed. R. W. Byrne \& A. Whiten. Clarendon Press/Oxford University Press.

di Pellegrino, G., Fadiga, L., Fogassi, L., Gallese, V. \& Rizzolatti, G. (1992) Understanding motor events: A neurophysiological study. Experimental Brain Research 91:176-180.

Dimberg, U. (1982) Facial reactions to facial expressions. Psychophysiology 19:643-647.

Dimberg, U. (1990) Facial electromyography and emotional reactions. Psychophysiology 27:481494.

Dimberg, U. \& Thunberg, M. (1998) Rapid facial reactions to emotion facial expressions. Scandinavian Journal of Psychology 39:39-46.

Dimberg, U., Thunberg, M. \& Elmehed, K. (2000) Unconscious facial reactions to emotional facial expressions. Psychological Science 11:86-89.

Doherty, R. W. (1997) The emotional contagion scale: A measure of individual differences. Journal of Nonverbal Behavior 21:131-154.

Dreyfus, H. L. (1996) The current relevance of Merleau-Ponty's phenomenology of embodiment. In: Perspectives on embodiment, ed. H. Haber \& G. Weiss. Routledge.

Einon, D. \& Potegal, M. (1994) Temper tantrums in young children. In: The dynamics of aggression: Biological and social processes in dyads and groups, ed. M. Potegal \& J. F. Knutson. Lawrence Erlbaum Associates, Inc.

Eisenberg, N. (1986) Altruistic emotion, cognition, and behavior. Lawrence Erlbaum Associates. 
Eisenberg, N., Fabes, R., Miller, P. A., Shell, R., Shea, C. \& May-Plumblee, T. (1990) Preschoolers' vicarious emotional responding and their situational and dispositional prosocial behavior. Merrill-Palmer Quarterly 36:507-529.

Eisenberg, N., Fabes, R. A., Bernzweig, J., Karbon, M., Poulin, R. \& Hanish, L. (1993) The relations of emotionality and regulation to preeschoolers' social skills and sociometric status. Child Development 64:1418-1438.

Eisenberg, N., Fabes, R. A., Murphy, B., Karbon, M., Maszk, P., Smith, M., O'Boyle, C. \& Suh, K. (1994) The relations of emotionality and regulation to dispositional and situational empathy-related responding. Journal of Personality \& Social Psychology 66:776-797.

Eisenberg, N., Fabes, R. A., Murphy, B., Karbon, M., Smith, M. \& Maszk, P. (1996) The relations of children's dispositional empathy-related responding to their emotionality, regulation, and social functioning. Developmental Psychology 32:195-209.

Eisenberg, N., Fabes, R. A., Schaller, M., Miller, P., Carlo, G., Poulin, R., Shea, C. \& Shell, R. (1991) Personality and socialization correlates of vicarious emotional responding. Journal of Personality \& Social Psychology 61:459-470.

Eisenberg, N., Lennon, R. \& Roth, K. (1983) Prosocial development: A longitudinal study. Developmental Psychology 19:846-855.

Eisenberg, N. \& Okun, M. A. (1996) The relations of dispositional regulation and emotionality to elders' empathy-related responding and affect while volunteering. Journal of Personality 64:157-183.

Eisenberg, N. \& Strayer, J. (eds.). (1987) Empathy and its development. Cambridge University Press.

Eisenberg, N., Wentzel, M. \& Harris, J. D. (1998) The role of emotionality and regulation in empathy-related responding. School Psychology Review 27:506-521.

Ekman, P., Levenson, R. W. \& Friesen, W. V. (1983) Autonomic nervous system activity distinguishes among emotions. Science 221:1208-1210.

Ekman, P., Sorenson, E. R. \& Friesen, W. V. (1969) Pan-cultural elements in facial displays of emotion. Science 164:86-88.

Eslinger, P. J. (1998) Neurological and neuropsychological bases of empathy. European Neurology 39:193-199.

Estes, W. K. \& Skinner, B. F. (1941) Some quantitative properties of anxiety. Journal of Experimental Psychology 29:390-400.

Farver, J. M. \& Branstetter, W. H. (1994) Preeschoolers' prosocial responses to the peers' distress. Developmental Psychology 30:334-341.

Feinman, S. (1982) Social referencing in infancy. Merrill-Palmer Quarterly 28:445-470.

Feshbach, N. D. (1975) Empathy in children: Some theoretical and empirical considerations. The Counseling Psychologist 5.

Feshbach, N. D. (1978) Studies of empathic behavior in children. In: Progress in Experimental Personality Research, ed. B. A. Maher. Academic Press.

Feshbach, N. D. \& Roe, K. (1968) Empathy in Six- and Seven-Year-olds. Child Development 39:133-145.

Field, T. (1994) The effects of mother's physical and emotional unavailability on emotion regulation. Monographs of the Society for Research in Child Development 59:208-227, 250-283. 
Field, T., Goldstein, S., Vega-Lahr, N. \& Porter, K. (1986) Changes in imitative behavior during early infancy. Infant Behavior \& Development 9:415-421.

Field, T., Healy, B. T., Goldstein, S. \& Guthertz, M. (1990) Behavior-state matching and synchrony in mother-infant interactions of nondepressed versus depressed dyads. Developmental Psychology 26:7-14.

Field, T., Healy, B. T. \& LeBlanc, W. G. (1989) Sharing and synchrony of behavior states and heart rate in nondepressed versus depressed mother-infant interactions. Infant Behavior \& Development 12:357-376.

Field, T., Pickens, J., Fox, N. A., Nawrocki, T. \& Gonzalez, J. (1995) Vagal tone in infants of depressed mothers. Development \& Psychopathology 7:227-231.

Field, T. M., Woodson, R., Greenberg, R. \& Cohen, D. (1982) Descrimination and imitation of facial expression by neonates. Science 218:179-181.

Finlay, B. L. \& Darlington, R. B. (1995) Linked regularities in the development and evolution of mammalian brains. Science 268:1578-1584.

Freud, S. (1922/1945) Group psychology and the analysis of the ego. Hogarth Press.

Freud, S. (1950) Collected works chronologically arranged: Works from the years 1932-1939. Imago Publishing Company.

Frijda, N. H. (1993) The place of appraisal in emotion. Cognition \& Emotion 7:357-387.

Frith, U. (1989) Autism: Explaining the Enigma. Blackwell.

Fuster, J., M. (1997) The prefrontal cortex: Anatomy, physiology, and neuropsychology of the frontal lobe. Lippincott-Raven Publishers.

Gable, S. \& Isabella, R. A. (1992) Maternal contributions to infant regulation of arousal. Infant Behavior \& Development 15:95-107.

Gallese, V. \& Goldman, A. (1998) Mirror neurons and the simulation theory of mind-reading. Trends in Cognitive Sciences 2:493-501.

Gallup, G. G. Jr. (1998) Self-awareness and the evolution of social intelligence. Behavioural Processes 42:239-247.

Gallup, G. G. Jr. (1979) Self-awareness in primates. American Scientist 67:417-421.

Gallup, G. G. Jr. (1992) Levels, limits, and precursors to self-recognition: Does ontogeny recapitulate phylogeny? Psychological Inquiry 3:117-118.

Gillberg, C. (1999) Neurodevelopmental processes and psychological functioning in autism. Development \& Psychopathology 11:567-587.

Gillberg, C. L. (1992) The Emanuel Miller Memorial Lecture 1991: Autism and autistic-like conditions: Subclasses among disorders of empathy. Journal of Child Psychology \& Psychiatry \& Allied Disciplines 33:813-842.

Goldie, P. (1999) How we think of others' emotions. Mind \& Language 14:394-423.

Goldstein, S., Field, T. \& Healy, B. T. (1989) Concordance of play behavior and physiology in preschool friends. Journal of Applied Developmental Psychology 10:337-351.

Gopnik, A. \& Meltzoff, A. N. (1994) Minds, bodies, and persons: Young children's understanding 
of the self and others as reflected in imitation and theory of mind research. In: Self-awareness in animals and humans: Developmental perspectives, ed. S. T. Parker \& R. W. Mitchell. Cambridge University Press.

Gottman, J. M. \& Levenson, R. W. (1985) A valid procedure for obtaining self-report of affect in marital interaction. Journal of Consulting \& Clinical Psychology 53:151-160.

Gouldner, A. (1960) The norm of reciprocity: A preliminary statement. American Sociology Review 47:73-80.

Grafton, S. T., Arbib, M. A., Fadiga, L. \& Rizzolatti, G. (1996) Localization of grasp representations in humans by positron emission tomography: Observation compared with imagination. Experimental Brain Research 112:103-111.

Grafton, S. T., Fadiga, L., Arbib, M. A. \& Rizzolatti, G. (1997) Premotor cortex activation during observation and naming of familiar tools. Neuroimage 6:231-236.

Gruen, R. J. \& Mendelsohn, G. (1986) Emotional responses to affective displays in others: The distinction between empathy and sympathy. Journal of Personality \& Social Psychology 51:609-614.

Gunnar, M. G., Fisch, R. O. \& Moline, S. (1984) The effects of a pacifying stimulus on behavioral adrenocortical responses to circumcision in the newborn. Journal of the American Academy of Child Psychiatry 23:34-38.

Gur, R. C., Skolnick, B. E. \& Gur, R. E. (1994) Effects of emotional discrimination tasks on cerebral blood flow: Regional activation and its relation to performance. Brain \& Cognition 25:271286.

Hamilton, W. D. (1964) The evolution of social behavior. Journal of Theoretical Biology 7.

Harlow, H. F. \& Harlow, M. (1966) Learning to love. American Scientist 54:244-272.

Harman, C. (1994) The interaction of distress and attention in early infancy. , University of Oregon, Eugene.

Harris, N. S., Courchesne, E., Townsend, J., Carper, R. A. \& Lord, C. (1999) Neuroanatomic contributions to slowed orienting of attention in children with autism. Cognitive Brain Research 8:6171.

Hatfield, E., Cacioppo, J. T. \& Rapson, R. L. (1993) Emotional contagion. Current Directions in Psychological Science 2:96-99.

Hillyard, S. A. (1993) Electrical and magnetic brain recordings: contributions to cognitive neurosciences. Current Opinion in Neurobiology 3:217-224.

Hobson, R. P. (1986a) The autistic child's appraisal of expressions of emotion. Journal of Child Psychology \& Psychiatry \& Allied Disciplines 27:321-342.

Hobson, R. P. (1986b) The autistic child's appraisal of expressions of emotion: A further study. Journal of Child Psychology \& Psychiatry \& Allied Disciplines 27:671-680.

Hobson, R. P. (1993) Autism and the development of mind. Lawrence Erlbaum Associates, Inc.

Hobson, R. P., Ouston, J. \& Lee, A. (1988) What's in a face? The case of autism. British Journal of Psychology 79:441-453.

Hobson, R. P., Ouston, J. \& Lee, A. (1989) Naming emotion in faces and voices: Abilities and disabilities in autism and mental retardation. British Journal of Developmental Psychology 7:237-250.

Hofer, M. A. (1995) Hidden regulators: Implications for a new understanding of attachment, 
separation, and loss. In: Attachment theory: Social, developmental, and clinical perspectives, ed. S. Goldberg, R. Muir, \& J. Kerr. Analytic Press.

Hofer, M. A. (1999) Psychobiological origins of attachment and separation responses. In: Handbook of attachment : Theory, research, and clinical applications, ed. J. Cassidy \& P. R. Shaver. Guilford Press.

Hoffman, M. L. (1978) Empathy: Its development and prosocial implications. In: Nebraska symposium on motivation: Social cognitive development, ed. J. H. E. Howe \& C. B. Keasey. University of Nebraska Press.

Hoffman, M. L. (1982) Affect and moral development. New Directions for Child Development 16:83-103.

Hoffman, M. L. (1990) Empathy and justice motivation. Motivation and Emotion 14:151-171.

Hommel, B. (1997) Interactions between stimulus-stimulus congruence and stimulus-response compatibility. Psychological Research/Psychologische Forschung 59:248-260.

Hommel, B. (1998) Automatic stimulus-response translation in dual-task performance. Journal of Experimental Psychology: Human Perception \& Performance 24:1368-1384.

Hornblow, A. R. (1980) The study of empathy. New Zealand Psychologist 9:19-28.

House, T. H. \& Milligan, W. L. (1976) Autonomic responses to modeled distress in prison psychopaths. Journal of Personality \& Social Psychology 34:556-560.

Howes, C. \& Farver, J. (1987) Toddler's response to the distress of their peers. Journal of Applied Developmental Psychology 8:441-452.

Hume, D. (1888/1990) A treatise of human nature. Clarendon Press.

Iacoboni, M., Woods, R. P., Brass, M., Bekkering, H., Mazziotta, J. C. \& Rizzolatti, G. (1999) Cortical mechanisms of imitation. Science 286:2526-2528.

James, W. (1884) What is an emotion? Mind 9:188-205.

James, W. (1890) The principles of psychology. Holt.

Jeannerod, M., Arbib, M. A., Rizzolatti, G. \& Sakata, H. (1995) Grasping objects: The cortical mechanisms of visuomotor transformation. Trends in Neurosciences 18:314-320.

Jeannerod, M. \& Frak, V. (1999) Mental imaging of motor activity in humans. Current Opinion in Neurobiology 9:735-739.

Johnson, M. (1987) The body in the mind: The bodily basis of meaning, imagination, and reason. The University of Chicago Press.

Jones, N. A., Field, T., Fox, N. A., Davalos, M., Lundy, B. \& Hart, S. (1998) Newborns of mothers with depressive symptoms are physiologically less developed. Infant Behavior \& Development 21:537-541.

Jones, V. \& Prior, M. (1985) Motor imitation abilities and neurological signs in autistic children. Journal of Autism and Developmental Disorders 15:37-45.

Kasari, C., Sigman, M., Mundy, P. \& Yirmiya, N. (1990) Affective sharing in the context of joint attention interactions of normal, autistic, and mentally retarded children. Journal of Autism \& Developmental Disorders 20:87-100.

Kenward, R. E. (1978) Hawks and doves: Factors affecting success and selection in goshawk attacks 
on wild pigeons. Journal of Animal Ecology 47:449-460.

Klinnert, M. D., Campos, J. J., Sorce, J. F., Emde, R. N. \& Svejda, M. (1983) Emotions as behavior regulators: Social referencing in infancy. In: Emotions in Early Development, ed. R. Plutchik \& H. Kellerman. Academic Press.

Kraemer, G. W. \& Clarke, A. S. (1996) Social attachment, brain function, and aggression. In: Understanding aggressive behavior in children, ed. C. F. Ferris \& T. Grisso. New York Academy of Sciences.

Krebs, D. (1970) Altruism - an examination of the concept and a review of the literature. Psychological Bulletin 73:258-302.

Krebs, D. (1975) Empathy and altruism. Journal of Personality and Social Psychology 32:11341146.

Kummer, H., Anzenberger, G. \& Hemelrijk, C. K. (1996) Hiding and perspective taking in longtailed macaques. Journal of Comparative Psychology 110:97-102.

Lamb, S. \& Zakhireh, B. (1997) Toddlers' attention to the distress of peers in a day care setting. Early Education \& Development 8:105-118.

Lane, R. D., Chua, P. M. L. \& Dolan, R. J. (1999) Common effects of emotional valence, arousal and attention on neural activation during visual processing of pictures. Neuropsychologia 37:989997.

Lavery, J. J. \& Foley, P. J. (1963) Altruism or arousal in the rat? Science 140:172-173.

van Lawick-Goodall, H. \& van Lawick-Goodall, J. (1971) Innocent Killers. Houghton Mifflin.

Lazarus, R. S. (1991) Cognition and motivation in emotion. American Psychologist 46:352-67.

Levenson, R. W. (1996) Biological substrates of empathy and facial modulation of emotion: Two facets of the scientific legacy of John Lanzetta. Motivation and Emotion 20:185-204.

Levenson, R. W. \& Reuf, A. M. (1992) Empathy: A physiological substrate. Journal of Personality and Social Psychology 63x:234-246.

Levine, S. (1990) The hormonal consequences of mother-infant contact. In: Touch: The foundation of experience: Full revised and expanded proceedings of Johnson \& Johnson Pediatric Round Table $X$., ed. K. E. Barnard \& T. B. Brazelton. International Universities Press, Inc.

Lhermitte, F., Pillon, B. \& Serdaru, M. (1986) Human autonomy and the frontal lobes: Part I. Imitation and utilization behavior: A neuropsychological study of 75 patients. Annals of Neurology 19:326-334.

Liebman, W. (1981) Infantile Colic: Association with lactose and mild intolerance. Journal of the American Medical Association 247:732-733.

Lilienfeld, S. O., Gershon, J., Duke, M., Marino, L. \& de Waal, F. B. M. (1999) A preliminary investigation of the construct of psychopathic personality (psychopathy) in chimpanzees (Pan troglodytes). Journal of Comparative Psychology 113:365-375.

Liotti, M. \& Tucker, D. M. (1995) Emotion in asymmetric corticolimbic networks. In: Brain Asymmetry, ed. R. J. Davidson \& K. Hugdahl. The MIT Press.

Lipps, T. (1903) Einfülung, innere Nachahmung und Organempfindung. Archiv für die gesamte Psychologie 1:465-519.

Lotze, R. H. (1852) Medicinische Psychologie oder Physiologie der Seele. Weidmann'sche 
Buchhandlung.

Loveland, K. A. \& Tunali, B. (1991) Social scripts for conversational interactions in autism and Down syndrome. Journal of Autism \& Developmental Disorders 21:177-186.

Loveland, K. A., Tunali-Kotoski, B., Chen, R., Brelsford, K. A., Ortegon, J. \& Pearson, D. A. (1995) Intermodal perception of affect in persons with autism or Down syndrome. Development \& Psychopathology 7:409-418.

Loveland, K. A., Tunali-Kotoski, B., Pearson, D. A., Brelsford, K. A., Ortegon, J. \& Chen, R. (1994) Imitation and expression of facial affect in autism. Development \& Psychopathology 6:433444.

Lundqvist, L.-O. \& Dimberg, U. (1995) Facial expressions are contagious. Journal of Psychophysiology 9:203-211.

Lundy, B., Field, T., Cigales, M. \& Cuadra, A. (1997) Vocal and facial expression matching in infants of mothers with depressive symptoms. Infant Mental Health Journal 18:265-273.

Lundy, B., Field, T. \& Pickens, J. (1996) Newborns of mothers with depressive symptoms are less expressive. Infant Behavior \& Development 19:419-424.

Macdonald, H., Rutter, M., Howlin, P., Rios, P., Le Conteur, A., Evered, C. \& Folstein, S. (1989) Recognition and expression of emotional cues by autistic and normal adults. Journal of Child Psychology \& Psychiatry \& Allied Disciplines 30:865-877.

Martin, G. B. \& Clark, R. D. (1982) Distress crying in neonates: Species and peer specificity. Developmental Psychology 18:3-9.

Masserman, J. H., Wechkin, S. \& Terris, W. (1964) "Altruistic" behavior in rhesus monkeys. American Journal of Psychiatry 121:584-585.

Maynard Smith, J. (1964) Group selection and kin selection. Nature 201:1145-1147.

McClelland, J. L. \& Rumelhart, D. E. (1985) Distributed memory and the representation of general and specific information. Journal of Experimental Psychology: General 114:159-188.

McDougall, W. (1908/1923) An Introduction to Social Psychology. Methuen \& Co. LTD.

Mead, G. H. (1934) Mind, self and society: from the standpoint of a social behaviorist. University of Chicago Press.

Meltzoff, A. N. (1993) The centrality of motor coordination and proprioception in social and cognitive development: From shared actions to shared minds. In: The development of coordination in infancy, ed. G. J. P. Savelsbergh. North-Holland/Elsevier Science Publishers.

Meltzoff, A. N. \& Moore, M. K. (1977) Imitation of facial and manual gestures by human neonates. Science 198:75-78.

Meltzoff, A. N. \& Moore, M. K. (1983) Newborn infants imitate adult facial gestures. Child Development 54:702-709.

Meltzoff, A. N. \& Moore, M. K. (1993) Early imitation within a functional framework: The importance of person identity, movement, and development. Annual Progress in Child Psychiatry \& Child Development:5-32.

Meltzoff, A. N. \& Moore, M. K. (1994) Imitation, memory, and the representation of persons. Infant Behavior \& Development 17:83-99.

Meltzoff, A. N. \& Moore, M. K. (1997) Explaining facial imitation: A theoretical model. Early 
Development \& Parenting 6:179-192.

Merleau-Ponty, M. (1962/1970) Phenomenology of perception. Routledge \& Kegan Paul/The Humanities Press.

Meyer, J. E. \& Thaler, M. M. (1971) Colic in low birth weight infants. American Journal of Diseases of Children 122:25-7.

Miller, J., Riehle, A. \& Requin, J. (1992) Effects of preliminary perceptual output on neuronal activity of the primary motor cortex. Journal of Experimental Psychology: Human Perception and Performance 18:1121-1138.

Miller, R. E., Banks, J. \& Ogawa, N. (1962) Communication of affect in "co-operative conditioning" of rhesus monkeys. Journal of Abnormal and Social Psychology 64:343-348.

Miller, R. E., Banks, J. \& Ogawa, N. (1963) Role of facial expression in "co-operative avoidance conditioning" of rhesus monkeys. Journal of Abnormal and Social Psychology 67:24-30.

Miller, R. E., Banks, J. H. J. \& Kuwahara, H. (1966) The communication of affects in monkeys: Cooperative reward conditioning. Journal of Genetic Psychology 108:121-134.

Miller, R. E., Caul, W. F. \& Mirsky, I. A. (1967) Communication of affect between feral and socially-isolated monkeys. Journal of Personality and Social Psychology 7:231-239.

Miller, R. E. \& Deets, A. C. (1976) Delta-9-thc and Nonverbal Communication in Monkeys. Psychopharmacology 48:53-58.

Miller, R. E., Murphy, J. V. \& Mirsky, I. A. (1959) Nonverbal Communication of Affect. Journal of Clinical Psychology 15:155-158.

Mineka, S. \& Cook, M. (1988) Social learning and the acquisition of snake fear in monkeys. In: Social learning: Psychological and biological perspectives, ed. T. R. Zentall \& B. G. G. Jr. Lawrence Erlbaum Associates, Inc.

Mineka, S. \& Cook, M. (1993) Mechanisms involved in the observational conditioning of fear. Journal of Experimental Psychology: General 122:23-38.

Mineka, S., Davidson, M., Cook, M. \& Keir, R. (1984) Observational conditioning of snake fear in rhesus monkeys. Journal of Abnormal Psychology 93:355-372.

Mirsky, I. A., Miller, R. E. \& Murphy, J. V. (1958) The communication of affect in rhesus monkeys. Journal of the American Psychoanalytic Association 6:433-441.

Mitchell, R. W., Thompson, N. S. \& Miles, H. L. (eds.). (1997) Anthropomorphism, anecdotes, and animals. State University of New York Press.

Morgan, S. B., Cutrer, P. S., Coplin, J. W. \& Rodrigue, J. R. (1989) Do autistic children differ from retarded and normal children in Piagetian sensorimotor functioning? Journal of Child Psychology and Psychiatry 30:857-864.

Mundy, P., Sigman, M. \& Kasari, C. (1994) The theory of mind and joint-attention deficits in autism. In: Understanding other minds: Perspectives from autism, ed. S. Baron-Cohen, H. TagerFlusberg, \& D. J. Cohen. Oxford University Press.

Mundy, P., Sigman, M. D., Ungerer, J. \& Sherman, T. (1986) Defining the social deficits of autism: The contribution of non-verbal communication measures. Journal of Child Psychology \& Psychiatry \& Allied Disciplines 27:657-669.

Murdock, G. K., Stine, W. W. \& Maple, T. L. (1983) Observations of maternal-infant interactions in a captive herd of sable antelope (Hippotragus niger). Zoo Biology 2:215-224. 
Murphy, L. B. (1937) Social behavior and child personality: An exploratory study of some roots of sympathy. Columbia University Press.

Nagel, T. (1974) What is it like to be a bat? Philosophical Review 83:435-50.

Nietzsche, F. W. (1895/1920) The Antichrist. A. A. Knopf.

O'Connell, S. M. (1995) Empathy in chimpanzees: Evidence for theory of mind? Primates 36:397410.

Ohta, M. (1987) Cognitive disorders of infantile autism: A study employing the WISC, spatial relationships, conceptualisations and gesture imitations. The Journal of Autism and Developmental Disorders 17:45-62.

Omdahl, B. L. (1995) Cognitive appraisal, emotion and empathy. Lawrence Erlbaum Associates.

Osofsky, J. D. (1971) Children's influences upon parental behavior: An attempt to define the relationship with the use of laboratory tasks. Genetic Psychology Monographs 83:147-169.

Ozonoff, S., Pennington, B. F. \& Rogers, S. J. (1990) Are there emotion perception deficits in young autistic children? Journal of Child Psychology \& Psychiatry \& Allied Disciplines 31:343-361.

Parr, L. A. (submitted) Cognitive and physiological markers of emotional awareness in chimpanzees (Pan troglodytes).

Parr, L. A. \& Hopkins, W. D. (in press) Brain temperature asymmetries and emotional perception in chimpanzees, Pan troglodytes. Physiology and Behavior.

Parsons, L. M. (1994) Temporal and kinematic properties of motor behavior reflected in mentally simulated action. Journal of Experimental Psychology: Human Perception \& Performance 20:709730.

Parsons, L. M., Fox, P. T., Downs, J. H., Glass, T., Hirsch, T. B., Martin, C. C., Jerabek, P. A. \& Lancaster, J. L. (1995) Use of implicit motor imagery for visual shape discrimination as revealed by PET. Nature 375:54-58.

Partan, S. \& Marler, P. (1999) Communication goes multimodal. Science 283:1272-1273.

Plutchik, R. (1987) Evolutionary bases of empathy. In: Empathy and its development., ed. N. Eisenberg \& J. Strayer. Cambridge University Press.

Potegal, M. \& Davidson, R. J. (1997) Young children's post tantrum affiliation with their parents. Aggressive Behavior 23:329-342.

Povinelli, D. J., Nelson, K. E. \& Boysen, S. T. (1992a) Comprehension of role reversal in chimpanzees: Evidence of empathy? Animal Behaviour 43:633-640.

Povinelli, D. J., Parks, K. A. \& Novak, M. A. (1992b) Role reversal by rhesus monkeys, but no evidence of empathy. Animal Behaviour 44:269-281.

Povinelli, D. J., Rulf, A. B. \& Bierschwale, D. T. (1994) Absence of knowledge attribution and self-recognition in young chimpanzees (Pan troglodytes). Journal of Comparative Psychology 108:74-80.

Povinelli, D. J., Rulf, A. B., Landau, K. R. \& Bierschwale, D. T. (1993) Self-recognition in chimpanzees (Pan troglodytes): Distribution, ontogeny, and patterns of emergence. Journal of Comparative Psychology 107:347-372.

Powell, G. V. N. (1974) Experimental analysis of the social value of flocking by starlings (Sturnus 
vulgarus) in relation to predation and foraging. Animal Behaviour 22:501-505.

Premack, D. \& Woodruff, G. (1978) Does the chimpanzee have a theory of mind? Behavioral and Brain Sciences 1:515-526.

Preston, S. D. \& de Waal, F. B. M. (submitted) The communication of emotions and the possibility of empathy in animals. In: Altruistic love: Science, philosophy, and religion in dialogue, ed. S. Post, L. G. Underwood, J. P. Schloss, \& W. B. Hurlburt.

Preston, S. D. \& Jacobs, L. F. (in press) Conspecific pilferage but no presence affects cache strategy in Merriam's kangaroo rats. Behavioral Ecology.

Prinz, W. (1987) Ideo-motor action. In: Perspectives on perception and action, ed. H. Heuer \& A. F. Sanders. Lawrence Erlbaum Associates, Inc,.

Prinz, W. (1992) Why don't we perceive our brain states? European Journal of Cognitive Psychology 4:1-20.

Prinz, W. (1997) Perception and action planning. European Journal of Cognitive Psychology 9:129154.

Prior, M. R. (1988) Biological and neuropsychological approaches to childhood autism. Annual Progress in Child Psychiatry \& Child Development:495-513.

Prior, M., Dahlstrom, B. \& Squires, T.-L. (1990) Autistic children's knowledge of thinking and feeling states in other people. Journal of Child Psychology \& Psychiatry \& Allied Disciplines 31:587601.

Radke-Yarrow, M., Zahn-Waxler, C. \& Chapman, M. (1983) Children's prosocial dispositions and behavior. In: Socialization, personality and social development, ed. E. M. Hetherington. Wiley.

Rice, G. E. J. (1964) Aiding behavior vs. fear in the albino rat. Psychological Record 14:165-170.

Rice, G. E. J. \& Gainer, P. (1962) "Altruism" in the albino rat. Journal of Comparative \& Physiological Psychology 55:123-125.

Ricks, D. M. (1979) Making sense of experience to make sensible sounds. In: Before speech: The beginning of interpersonal communication, ed. M. Bullowa. Cambridge University Press.

Rizzolatti, G. \& Arbib, M. A. (1998) Language within our grasp. Trends in Neurosciences 21:188194.

Rosch, E. (1988) Principles of categorization. In: Readings in cognitive science: A perspective from psychology and artificial intelligence, ed. A. M. Collins \& E. E. Smith. Morgan Kaufmann, Inc.

Rosch, E. \& Mervis, C. B. (1975) Family resemblances: Studies in the internal structure of categories. Cognitive Psychology 7:573-605.

Rosch, E. H. (1973) Natural categories. Cognitive Psychology 4:328-350.

Rosekrans, M. A. (1967) Imitation in children as a function of perceived similarity to a social model and vicarious reinforcement. Journal of Personality and Social Psychology 7:307-315.

Rothbart, M. K., Posner, M. I. \& Rosicky, J. (1994) Orienting in normal and pathological development. Development and Psychopathology 6:635-652.

Rowell, P. A. (1978) Infantile colic: Reviewing the situation. Pediatric Nursing 4:20-21.

Sagi, A. \& Hoffman, M. L. (1976) Empathic distress in the newborn. Developmental Psychology 12:175-176. 
Sawyer, J. (1966) The altruism scale: A measure of co-operative, individualistic, and competitive interpersonal orientation. American Journal of Sociology 71:407-416.

Schwartz, G. E., Davidson, R. J. \& Maer, F. (1975) Right hemisphere lateralization for emotion in the human brain: Interactions with cognition. Science 190:286-288.

Scott, S., K., Young, A. W., Calder, A. J., Hellawell, D. J., Aggleton, J. P. \& Johnson, M. (1997) Impaired auditory recognition of fear and anger following bilateral amygdala lesions. Nature 385:254257.

Shantz, C. U. (1975) The development of social cognition. In: Review of Child Development Research, ed. E. M. Hetherington. University of Chicago Press.

Sherman, P. W. (1977) Nepotism and the evolution of alarm calls. Science 197:1246-1253.

Shiamamura, A. P. (1996) The role of the prefrontal cortex in controlling and monitoring memory processes. In: Metacognition and Implicit Memory, ed. L. Reder. Erlbaum Press.

Sigman, M. \& Ruskin, E. (1999) Continuity and change in the social competence of children with autism, Down syndrome, and developmental delays. Monographs of the Society for Research in Child Development 64:v-114.

Sigman, M. D., Kasari, C., Kwon, J.-h. \& Yirmiya, N. (1992) Responses to the negative emotions of others by autistic, mentally retarded, and normal children. Child Development 63:796-807.

Sigman, M. D., Mundy, P., Sherman, T. \& Ungerer, J. (1986) Social interactions of autistic, mentally retarded and normal children and their caregivers. Journal of Child Psychology \& Psychiatry \& Allied Disciplines 27:647-656.

Simner, M. L. (1971) Newborn's response to the cry of another infant. Developmental Psychology 5:136-150.

Singer, J. A. \& Salovey, P. (1988) Mood and memory: Evaluating the Network Theory of Affect. Clinical Psychology Review 8:211-251.

Smith, A. (1759) A theory of moral sentiments. Clarendon Press.

Smith, D. W. (1989) The circle of acquaintance: Perception, consciousness and empathy. Kluwer Academic Publishers.

Smith, K. D. (1992) Trait sympathy and perceived control as predictors of entering sympathyarousing situations. Personality and Social Psychology Bulletin 18:207-216.

Smotherman, W. P., Bell, R. W., Hershberger, W. A. \& Coover, G. D. (1978) Orientation to rat pup cues: Effects of maternal experiential history. Animal Behaviour 26:265-273.

Sorce, J. F., Emde, R. N., Campos, J. J. \& Klinnert, M. D. (1985) Maternal emotional signaling: Its effect on the visual cliff behavior of 1-year-olds. Developmental Psychology 21:195-200.

Spizzichino, C. \& Bonaiuto, M. (1990) Mood and cognition: A pilot study of individual differences. Archivio di Psicologia, Neurologia e Psichiatria 51:75-84.

Stern, D. (1974) The goal structure of mother-infant play. Journal of the American Academy of Child Psychology 13:402-421.

Stern, D. (1977) The first relationship: Infant and mother. Harvard University Press.

Stinson, L. \& Ickes, W. (1992) Empathic accuracy in the interactions of male friends versus male strangers. Journal of Personality \& Social Psychology 62:787-797. 
Tantam, D., Monaghan, L., Nicholson, H. \& Stirling, J. (1989) Autistic children's ability to interpret faces: A research note. Journal of Child Psychology and Psychiatry 30:623-630.

Taylor, K. \& Stein, J. (1999) Attention, intention and salience in the posterior parietal cortex. Neurocomputing: An International Journal 26:901-910.

Temerlin, M. K. (1975) Lucy: Growing up human. Science and Behavior Books.

Thierry, A.-M., Glowinsky, J., Goldman-Rakic, P. S. \& Christen, Y. (1994) Motor and cognitive functions of the prefrontal cortex. Springer-Verlag.

Thompson, R. A. (1987) Empathy and emotional understanding: The early development of empathy. In: Empathy and its development, ed. N. Eisenberg \& J. Strayer. Cambridge University Press.

Tipper, S. P. (1985) The negative priming effect: Inhibitory priming by ignored objects. Quarterly Journal of Experimental Psychology Section A Human Experimental Psychology 37:571-590.

Tipper, S. P. \& Cranston, M. (1985) Selective attention and priming: Inhibitory and facilitatory effects of ignored primes. Quarterly Journal of Experimental Psychology Section A Human Experimental Psychology 37:591-612.

Titchener, E. (1909) Experimental psychology of the thought processes. Macmillan.

Titchener, E. (1915) A beginner's psychology. Macmillan.

Toi, M. \& Batson, C. D. (1982) More evidence that empathy is a source of altruistic motivation. Journal of Personality and Social Psychology 43:281-292.

Tomasello, M. \& Call, J. (1997) Primate cognition. Oxford University Press.

Tomkins, S. S. (1962) Affect, imagery, consciousness: Vol. I. The positive affects. Springer.

Trivers, R. L. (1971) The evolution of reciprocal altruism. Quarterly Review of Biology 46:35-57.

Tronick, E. Z. (1989) Emotions and emotional communication in infants. American Psychologist 44:112-119.

Ungerer, J. A. (1990) The early development of empathy: Self-regulation and individual differences in the first year. Motivation and Emotion 14:93-106.

de Waal, F. B. M. (1982) Chimpanzee politics : power and sex among apes. Jonathan Cape.

de Waal, F. B. M. (1989) Peacemaking among primates. Harvard University Press.

de Waal, F. B. M. (1996) Good natured: the origins of right and wrong in humans and other animals. Harvard University Press.

de Waal, F. B. M. (1997a) Are we in anthropodenial? Discover 18:50-53.

de Waal, F. B. M. (1997b) Bonobo : The forgotten ape. University of California Press.

de Waal, F. B. M. \& Aureli, F. (1996) Consolation, reconciliation and a possible cognitive difference between macaqes and chimpanzees. Cambridge University Press.

de Waal, F. B. M., Uno, H., Luttrell, L. M., Meisner, L. F. \& Jeanotte, L. A. (1996) Behavioral retardation in a Macaque with autosomal trisomy and aging mother. American Journal on Mental Retardation 100:378-390.

de Waal, F. B. M. \& van Roosmalen, A. (1979) Reconciliation and consolation among chimpanzees. 
Behavioral Ecology and Sociobiology 5:55-66.

Watanabe, S. \& Ono, K. (1986) An experimental analysis of "empathic" response: Effects of pain reactions of pigeon upon other pigeon's operant behavior. Behavioural Processes 13:269-277.

Wechkin, S., Masserman, J. H. \& Terris, W., Jr. (1964) Shock to a conspecific as an aversive stimulus. Psychonomic Science 1:47-48.

Wentura, D. (1999) Activation and inhibition of affective information: Evidence for negative priming in the evaluation task. Cognition \& Emotion 13:65-91.

Wermlund, S. (1949) William McDougall's theory of primitive sympathy. Theoria 15:384-398.

Wiesenfeld, A. R. \& Klorman, R. (1978) The mother's psychophysiological reactions to contrasting affective expressions by her own and an unfamiliar infant. Developmental Psychology 14:294-304.

Wispé, L. (1986) The distinction between sympathy and empathy: To call forth a concept, a word is needed. Journal of Personality \& Social Psychology 50:314-321.

Wispé, L. (1987) History of the concept of empathy. In: Empathy and its development, ed. N. Eisenberg \& J. Strayer. Cambridge University Press.

Wispé, L. (1991) The psychology of sympathy. Plenum Press.

Wohlschläger, A. \& Wohlschläger, A. (1998) Mental and manual rotation. Journal of Experimental Psychology: Human Perception and Performance 24:397-412.

Yarrow, M. R., Waxler, L. Z. \& Scott, P. M. (1971) Children's effects on adult behavior. Developmental Psychology 5:300-311.

Yerkes, R. M. \& Yerkes, A. W. (1929) The great apes: A study of anthropoid life. Yale University Press.

Yirmiya, N., Kasari, C., Sigman, M. \& Mundy, P. (1989) Facial expressions of affect in autistic, mentally retarded and normal children. Journal of Child Psychology \& Psychiatry \& Allied Disciplines 30:725-735.

Yirmiya, N., Sigman, M. D., Kasari, C. \& Mundy, P. (1992) Empathy and cognition in highfunctioning children with autism. Child Development 63:150-160.

Zahn-Waxler, C., Hollenbeck, B. \& Radke-Yarrow, M. (1984) The origins of empathy and altruism. In: Advances in Animal Welfare Science, ed. M. W. Fox \& L. D. Mickley. Humane Society of the United States.

Zahn-Waxler, C., Iannotti, R. \& Chapman, M. (1982) Peers and prosocial development. Peer relationships and social skills in childhood.

Zahn-Waxler, C., Radke-Yarrow, M. \& King, R. A. (1977) The impact of the affective environment on young children. Paper presented at the Society for Research in Child Development, New Orleans.

Zahn-Waxler, C., Radke-Yarrow, M., Wagner, E. \& Chapman, M. (1992) Development of concern for others. Developmental Psychology 28:126-136. 